\title{
The Methodology of Thermal Energy Management for Nearly Zero Energy Buildings
}

\author{
Dariusz Heim ${ }^{1 *}$, Marek Pawłowski² \\ ${ }^{1}$ Department of Environmental Engineering, \\ Faculty of Process and Environmental Engineering, \\ Lodz University of Technology, \\ ul. Wolczanska 213, 90-924 Lodz, Poland \\ 2 Department of Electrical Apparatus, \\ Faculty of Electrical, Electronic, Computer and Control Engineering, \\ Lodz University of Technology, \\ ul. Stefanowskiego 18/22, 90-924 Lodz, Poland \\ ${ }^{*}$ Corresponding author, e-mail: dariusz.heim@p.lodz.pl
}

Received: 09 August 2018, Accepted: 28 January 2019, Published online: 09 April 2019

\begin{abstract}
Distributed generation causes an unbalanced power grid, which leads to a problem with unpredicted energy surplus balancing. In this vast problem, active cooperation with individual consumers on the energy market is crucial to ensure stability of the power system. Therefore, basing on analysis of power demand for the power system, the control algorithm of Thermal Energy Management System for the net Zero Energy Buildings was developed. One of the possibility of shifting peak power demand is using a building structure as a thermal energy storage. The potential of energy management was confirmed by numerical analysis of two nearly zero energy building models (a heavy and a light construction). A heavy construction building consumes less energy than a light construction but possibilities of obtaining measurable cost savings for user are higher in a case of light construction building. The objective of this study is to show that it is possible to save about $17-28 \%$ of the yearly cost of electricity by using the proposed control algorithm. On the contrary, lack of active and conscious usage will result in yearly increase of energy costs at the level of 5-8\%. At the same time functioning of the HVAC system according to the proposed algorithm does not significantly effects on thermal comfort.
\end{abstract}

\section{Keywords}

building automation, demand-side management, energy management, energy storage, thermal factors, thermal management

\section{Introduction}

The increase in energy demand determines the increased output of fuels resources. Therefore, in the European Union and all around the World the policies that promote environmentally friendly solutions are clearly visible, including policies improving energy efficiency and the use of renewable energy sources. The key issue becomes not only the energy generation, but its distribution as well. Dynamic changes in power demand and the stochastic nature of the productivity of some renewable energy sources can cause a situation of a significant overload of the power system or a power shortage, which can result e.g. in a black-out. These situations can be defined as a problem of energy flow balance in the power system. In such concept the biggest problem is not the amount of energy generated or consumed, but the time in which energy is going to be received from a source or delivered to a recipient. The consequences of power unbalancing are very serious, both to ensure power system stability as well as economic terms for the producers and suppliers of energy. The technical condition of the infrastructure of the power system in many countries is insufficient to ensure the reliability of supply. One of the solutions to the above problems is demand-side management (DSM) mechanisms with Time-of-Use tariffs, which relies on effective management of power demand and load shifts to a different period of time, usually in a daily cycle.

The main goal of the DSM mechanisms is not to reduce energy consumption, but to shift the energy consumption to off-peak zones [1]. Perez-Lombard et al. pointed out that buildings are responsible for $20 \%$ to $40 \%$ of final energy consumption $[2,3]$, while residential buildings represents 
$80 \%$ of the total. These values confirm the potential that lies in the individual consumers if they are active player of the energy market. Progress in an intelligent and energy-efficient building promotes the development of building energy management systems.

According to the current and anticipated future trends in energy consumption the building sector facing strong challenges in system technology. The great potential in energy savings is associated with building management system and utilization of energy from renewable sources, especially electricity produced on-side. These two factors mentioned above cause that the share of electrical energy became dominant in comparison with heat or cool produced directly from fossil fuels. Additionally, in modern HVAC systems the auxiliary energy consumption for mechanical devices rises in comparison to energy for heating and cooling.

According to the idea of low energy or even net Zero Energy Building (nZEB) most of the building's systems are based on electricity and are designed to share, deliver and export energy to/from the grid. Even if the building does not generate on-site any extra power its HVAC system needs this form of energy as auxiliary to supply plant components. The universal devices currently installed in nZEB buildings are solar collectors, mechanical ventilation units with heat recovery and ground or air source heat pumps. This trend caused that heating/cooling demand is covered in $100 \%$ by electrical devices or thermal renewable energy systems supplied by electricity.

Taking into account a daily profile of electricity demand it seems to be justified that an adjustment of the residential sector can reduce the critical peak of energy demand if modification of demand profile is performed. This shifting would be possible only by taking into account physical characteristics of a building, its thermal inertia and indoor thermal comfort requirements.

The objective of this study is to develop a control algorithm of the Thermal Energy Management System (TEMS) for the net Zero Energy Buildings. The algorithm takes into account the current Time-of-Use tariff and thermal comfort conditions of users. The developed control algorithm of TEMS has been implemented in the HVAC components. Therefore, electrical energy consumption and different power profiles are considered. The whole year analyses were done for two types of single family houses using dynamic simulation method.

The following aspects and results were presented in particular sections. The Section 2 contains the state of the art of the electric power system, which was used for the deve- lopment of the new control algorithm of TEMS presented in the Section 3. In the Section 4 analysis of energy performance and thermal behaviours of new building were shown. Using numerical analysis two buildings models were deve-loped, examined and compared. The Section 5 comprises the results of a building performance analysis including daily power demand profiles distribution. Definition of the effect of intermittent heating/cooling on final energy use, energy costs and thermal comfort were shown in the Section 6. The result analysis, final discussions and conclusions are presented in the Section 7 and 8 respectively.

\section{Electric power system}

Technological and economic development of countries determines the increased of energy demand. The growth in the share of renewable energy sources in the energy balance is an undeniable fact. This determines the development of distributed energy, where the key is not only the amount of energy delivered, but the time of its delivery and quality of energy. The aforementioned factors result in the necessity to adapt and consequently to develop the infrastructure of generation and energy transmission. These efforts are mainly focused on research on the implementation of smart power grids. One of the basic assumptions of the smart grids is to involve the end user who should play an active role in the energy market which may be implemented through the mechanisms of DSM [4-8]. The study of consumer behavior concerning the use of electricity clearly indicates that the energy savings based on changing habits of users can achieve maximum improvement in energy efficiency of municipal buildings [9-13]. The concept of smart grids and the integration of individual consumers require the development of advanced energy management systems [14-18].

The power demand of the power system is a value relatively well-known and predictable depending on the day of the week or period during the year. As a result, it was possible to plan the energy production profile, including periods of peak power demand, which required the start-up of additional units. However, the balance of power system is disturbed by increasing the share of renewable energy sources, in particular sources with stochastic nature of production (wind turbines, photovoltaic panels). Therefore, in the power system, significant energy surplus or shortage may be observed. Both situations are extremely dangerous for the stability and safety of the power system. One of the solution to solve the problem is an energy storage 
that provides a buffer in both cases. Unfortunately, to date, apart from pumped-storage hydroelectric power plants, there is no other cost-effective energy storage solutions in a scale of commercial power industry.

The demand-side management depends on effective stimulation of energy consumption. Reducing energy consumption at the time of peak demand contributes to the achievement of the balance between demand and supply in the system which affects the market price of electricity. The implementation of mechanism that allows the end users the voluntary adjustment of demand will affect the Demand Response (DR), which is a real and effective demand management strategy.

An attempt to solve the problem of energy storage are DSM mechanisms. In the traditional approach, the aim of the energy storage is to accumulate the excess of energy and use it in periods of increased energy demand. The purpose of the DSM is distributing the energy demand for periods of increased production from conventional or renewable sources. In this way the electricity receivers, as well as the HVAC system supported building thermal mass and installation capacity are becoming virtual energy storages. The load can become virtual storage thanks to the option of delaying start of the device in time. Compared with the traditional storage, the efficiency of virtual storage is equal to $100 \%$ since there are no losses resulting from the conversion of energy [4, 19]. In addition, there is no central unit that could work improperly, as a result of failure, affect the entire system.

A certain potential is also in the building itself through the ability to store heat in its structure [20, 21]. Hasnain S. M. [22] pointed out the storage in building fabric as the possibility of energy storage systems in surface heating (underfloor heating). G. P. Henze et al. [23] displayed that buildings can respond to energy pricing signals by shifting cooling-related thermal loads either by precooling the building's massive structure or by using active thermal energy storage systems such as ice storage. Heim [24] and Pomianowski et al. [25] showed the additional effect of latent heat storage by building construction modified with phase change materials (PCM). The papers written by Cui et al. [26] and Sun et al. [27] presents the investigations on the power demand alternation potential for buildings involving both active and passive cold storages to support the demand response of buildings connected to smart grids. Feasibility and potential of thermal demandside management in residential building was considered by Wolisz et al. [28].
Finn and Fitzpatrick [29] analysed the potential for the implementation of price based demand response by an industrial consumer to increase their proportional use of wind generated electricity. It was found that a $10 \%$ reduction in a consumer's average unit price due to the implementation of price incentivized DR typically results in an increase in consumption of wind generation of approximately $5.8 \%$. The combination of DSM and tariffs significantly improves safety and reduces the cost of the power system with a large share of wind power.

There are two types of DSM: passive and active [20]. In the first one, the consumer only receives signals encouraging certain activities and the operator of the electricity grid does not have a direct impact on the consumer's devices. In the case of an active DSM, the consumer allows direct interaction of the network operator and the selected devices in the specified range. The consumer determines the possibility of switching on and off of the selected devices at certain times. Similarly, [4] define two types of demand response: Market DR and Physical DR. The Market DR includes the market activities: changing electricity prices and thus stimulating consumers to specific behaviours. However, according to Palensky and Dietrich [4], this is not sufficient to optimize the network in terms of stability. Hence, there exists the need for physical DR actions that can send directly controlling signals to the consumer in order to enforce certain changes.

Practical implementation of DSM mechanisms can be realised using suitably constructed tariffs with Price Responsive Demand programs. In the literature [30, 31] detailed information may be found about Time-of-Use (TOU), Real Time Pricing (RTP) RTP + CPP Critical Peak Pricing tariffs.

The development of DSM mechanisms and new energy tariffs require a detailed analysis of the profiles of the power demand from the power system. Fig. 1 presents profiles of the power demand of the Polish power system and

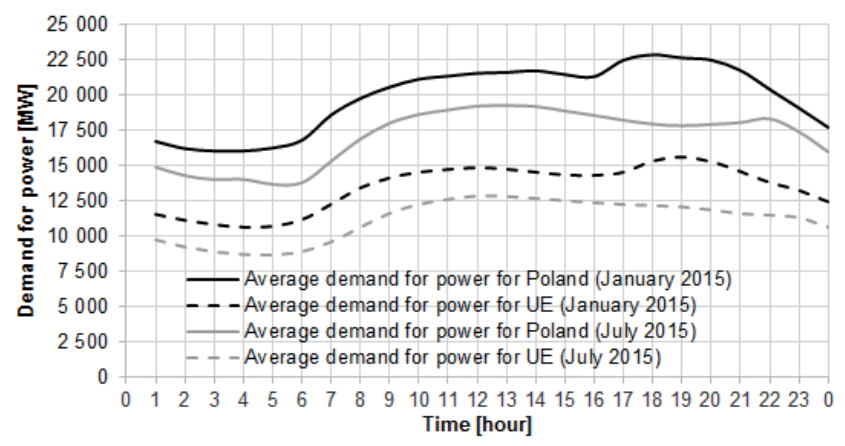

Fig. 1 Average power demand in Poland and in the EU [33] 
the average values for the European Union in January and July. Despite the differences in value, it should be noted that the shape of the curves and their mutual dependencies are similar. Thus, the value of power demand in Poland may serve as an example for the further analysis.

\section{The control algorithm of TEMS}

\subsection{Analysis of power demand profiles}

Detailed analysis of the profile of the power demand of the Power System allows for a new approach in development of electricity tariffs for individual consumers. Fig. 2 present profiles of the power demand of the Polish power system in the year 2015 .

Throughout the year, the hour of the morning increase in demand for power is practically constant and oscillates around 06.00 hours. An increase in demand for power takes place over nearly two hours, to about 08.00. Due to the similar values and shapes of the curves, it is possible to select three periods: the winter period (November-February), the spring/autumn period (March, April, September, October) and the summer period (May-August). Figs. 3, 4 and 5 present power demand of the power system in three separate periods. Fig. 6 presents the average value of the power demand for each period during the year. Based on the analysis of the charts (Fig. 6) we can divide power demand into periods of higher and lower demand. Periods of increased demand was called a midday and evening peak. Time between these two periods was named afternoon trough.

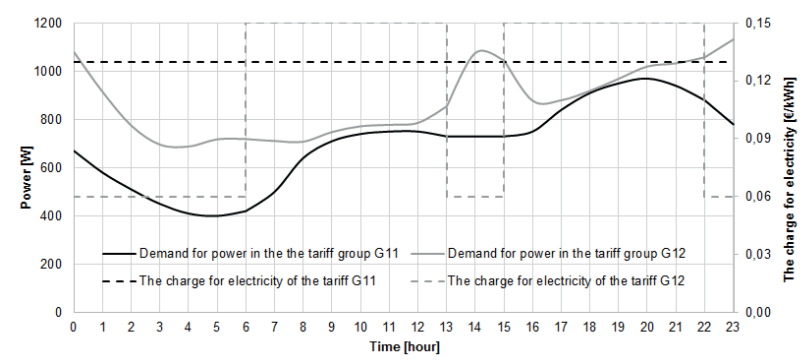

Fig. 2 The demand for power in the Polish Power System (2015) [33]

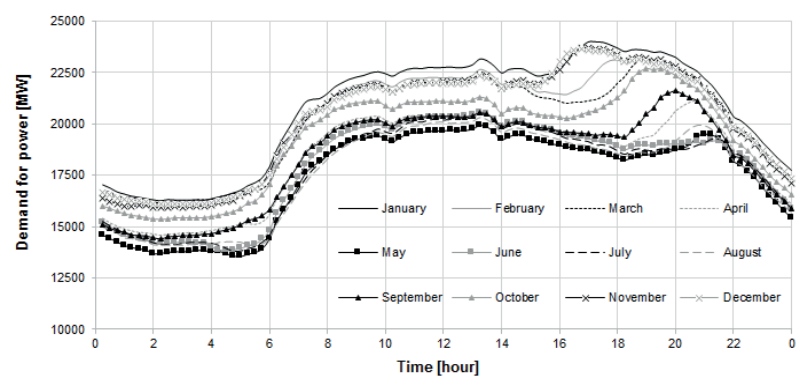

Fig. 3 The demand for power in the winter period (2015) [33]

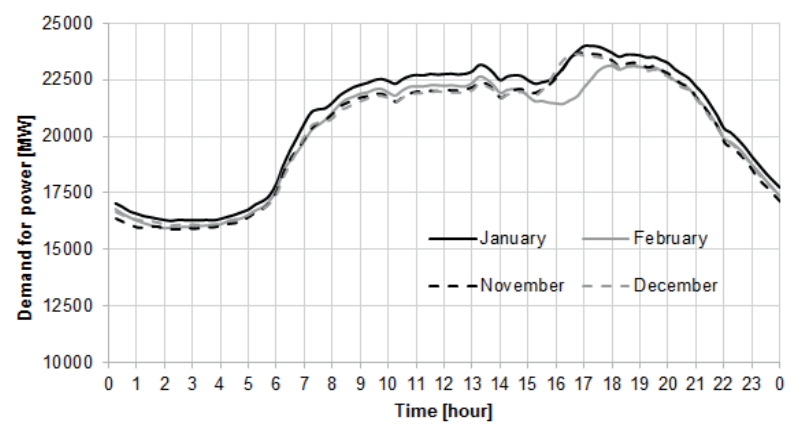

Fig. 4 The demand for power in the spring/autumn period (2015) [33]

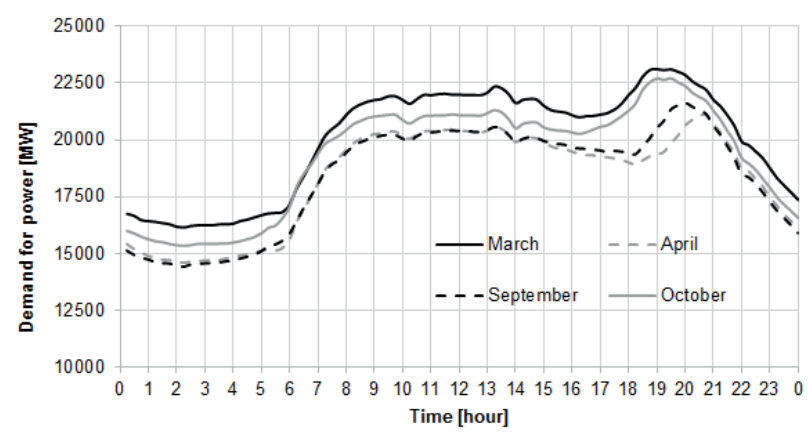

Fig. 5 The demand for power in the summer period (2015) [33]

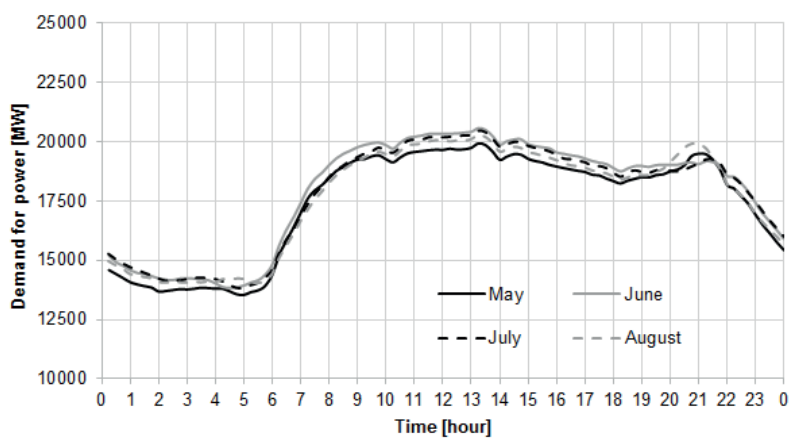

Fig. 6 The average demand for power in the winter, spring/autumn and summer periods (2015) [33]

The analysis of the energy market indicates that the tariffs with only two rates are not sufficient to involve consumer in energy market. Therefore, the authors suggest three distinct rates for electricity, taking into account the different periods of the day and the year. Based on the analysis, Table 1 presents the suggested indicators of energy prices dependent on the period of the year and time of the day.

\subsection{Assumptions and Objectives of the Algorithm}

The basic assumption of the TEMS in the building is to maintain thermal comfort of building users. This problem is a very common in any types of passive [32] or zero energy houses. Thermal comfort level were also considered as the design objective in an optimisation analysis [33]. In the case of the integration of the building with the smart grid, the temporal reduction of their power consumption is 
Table 1 The array of the energy price $\mathrm{C}$ for selected seasons, $\mathrm{L}-$ low, $\mathrm{N}-$ regular and $\mathrm{H}$ - high energy prices

\begin{tabular}{|c|c|c|c|}
\hline \multirow{2}{*}{ hour } & \multicolumn{3}{|c|}{ The array $\mathrm{C}$ for period: } \\
\hline & winter & summer & spring/autumn \\
\hline 00:00 - 01:00 & $\mathrm{L}$ & $\mathrm{L}$ & $\mathrm{L}$ \\
\hline 01:00 - 02:00 & $\mathrm{L}$ & $\mathrm{L}$ & $\mathrm{L}$ \\
\hline 02:00 - 03:00 & $\mathrm{L}$ & $\mathrm{L}$ & $\mathrm{L}$ \\
\hline 03:00 - 04:00 & $\mathrm{L}$ & $\mathrm{L}$ & $\mathrm{L}$ \\
\hline 04:00 - 05:00 & $\mathrm{L}$ & $\mathrm{L}$ & $\mathrm{L}$ \\
\hline 05:00 - 06:00 & $\mathrm{L}$ & $\mathrm{L}$ & $\mathrm{L}$ \\
\hline 06:00 - 07:00 & $\mathrm{N}$ & $\mathrm{N}$ & $\mathrm{N}$ \\
\hline 07:00 - 08:00 & $\mathrm{N}$ & $\mathrm{N}$ & $\mathrm{N}$ \\
\hline 08:00 - 09:00 & $\mathrm{N}$ & $\mathrm{N}$ & $\mathrm{N}$ \\
\hline 09:00 - 10:00 & $\mathrm{N}$ & $\mathrm{L}$ & $\mathrm{N}$ \\
\hline $10: 00-11: 00$ & $\mathrm{~N}$ & $\mathrm{~L}$ & $\mathrm{~N}$ \\
\hline $11: 00-12: 00$ & $\mathrm{~N}$ & $\mathrm{H}$ & $\mathrm{N}$ \\
\hline $12: 00-13: 00$ & $\mathrm{~N}$ & $\mathrm{H}$ & $\mathrm{N}$ \\
\hline $13: 00-14: 00$ & $\mathrm{~N}$ & $\mathrm{H}$ & $\mathrm{N}$ \\
\hline $14: 00-15: 00$ & $\mathrm{~L}$ & $\mathrm{~N}$ & $\mathrm{~N}$ \\
\hline $15: 00-16: 00$ & $\mathrm{~L}$ & $\mathrm{~N}$ & $\mathrm{~N}$ \\
\hline $16: 00-17: 00$ & $\mathrm{H}$ & $\mathrm{N}$ & $\mathrm{L}$ \\
\hline $17: 00-18: 00$ & $\mathrm{H}$ & $\mathrm{L}$ & $\mathrm{L}$ \\
\hline 18:00 - 19:00 & $\mathrm{H}$ & $\mathrm{L}$ & $\mathrm{H}$ \\
\hline 19:00 - 20:00 & $\mathrm{N}$ & $\mathrm{N}$ & $\mathrm{H}$ \\
\hline $20: 00-21: 00$ & $\mathrm{~N}$ & $\mathrm{~N}$ & $\mathrm{H}$ \\
\hline $21: 00-22: 00$ & $\mathrm{~N}$ & $\mathrm{~N}$ & $\mathrm{~N}$ \\
\hline $22: 00-23: 00$ & $\mathrm{~L}$ & $\mathrm{~L}$ & $\mathrm{~L}$ \\
\hline $23: 00-00: 00$ & $\mathrm{~L}$ & $\mathrm{~L}$ & $\mathrm{~L}$ \\
\hline
\end{tabular}

required which in turn may lead to a deterioration of thermal conditions. This is due to the need of the peak load reduction and transfer of power into off-peak periods.

The temporary discomfort is compensated in the DSM programs and in energy tariffs by reducing energy costs. Unfortunately, such operation of TEMS from the user point of view is uncomfortable. Therefore the consumers are forced to choose between economic savings and thermal comfort level. In addition, the TEMS should take into account requirements related to the integration of the building with the smart grid. The purpose of the developed algorithm is to achieve a compromise between the requirements of consumers and the power system.

This assumption can be written as four objective functions (1-4). The indexes refers to hour $(i)$ and day $(d)$ respectively. First, the algorithm seeks to minimize the costs of energy consumed by the users (1). Secondly, the algorithm minimizes the impact of the TEMS on the thermal comfort of the users (2). Predicted Mean Votes (PMV) index was used for an objective assessment of a level of a thermal comfort of users. Thirdly, the algorithm evaluates the function of peak shaving, which minimizes the amount of energy used during peak demand periods (3). Consequently, TEMS is also responsible for the transfer of loads in off-peak periods and thus determines the function of peak shifting which maximizes the amount of energy consumed in off-peak periods (4).

$$
\begin{aligned}
& \min \sum_{d=1}^{365} \sum_{i=1}^{24} c_{i}^{d} E_{i}^{d}, \\
& \min \sum_{d=1}^{365} \sum_{i=1}^{24}\left(P M V_{i}^{d}<-1.0 \vee P M V_{i}^{d}>1.0\right), \\
& \min \sum_{d=1}^{365} E_{H P}^{d}, \\
& \max \frac{\sum_{d=1}^{365} E_{L P}^{d}}{\sum_{d=1}^{24} \sum_{i=1}^{24} E_{i}^{d}}
\end{aligned}
$$

where: $c_{i}^{d}$-energy price, $E_{i}^{d}$ - energy consumed by HVAC system, $P M V_{i}^{d}$ - predicted mean vote, $E_{H P}^{d}-$ energy consumed in HP period, $E_{L P}^{d}$ - energy consumed in LP period.

The developed control algorithm of TEMS has been implemented in the HVAC components. Its corresponding flowcharts for the winter and summer periods for a single day are presented respectively in Figs. 7 and 8.

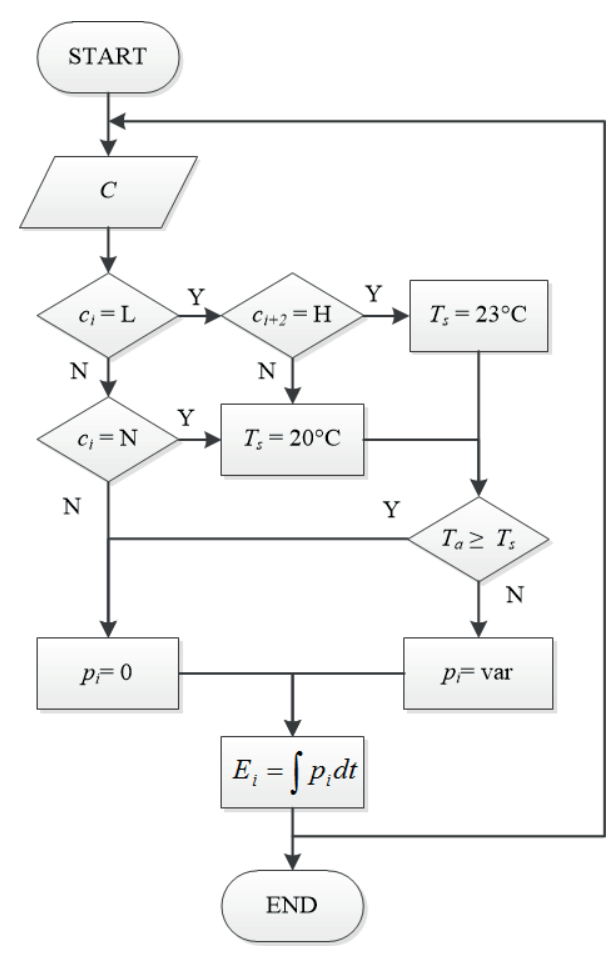

Fig. 7 The control algorithm of TEMS for winter 


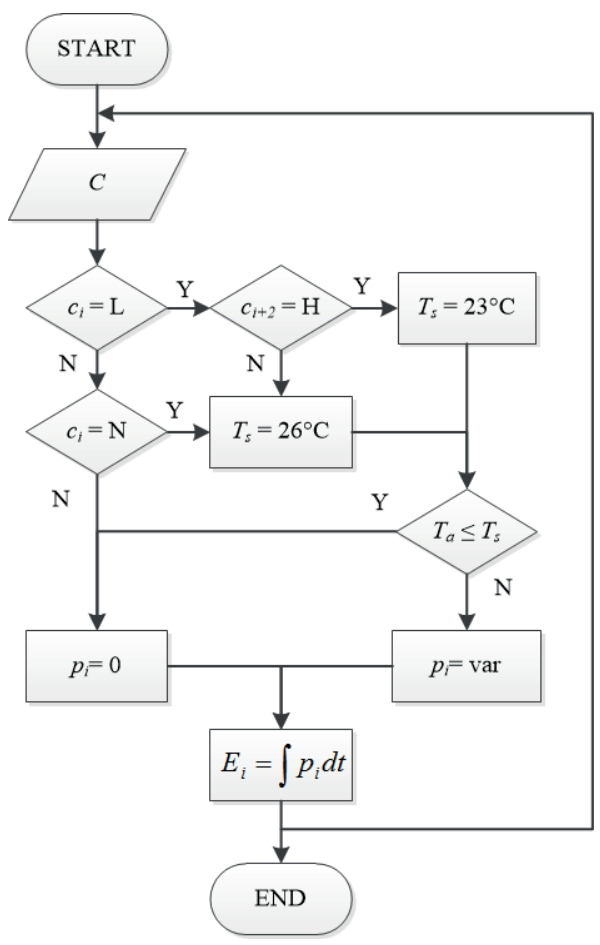

Fig. 8 The control algorithm of TEMS for summer

It is assumed that in the spring / autumn period the energy consumed by the HVAC system is negligible. Information on current energy price $\left(c_{i}\right)$ is collected from the array $C$. According to the Table 1 there are three rates for energy: Low (L), Normal (N) and High (H). If a price for energy at $i$-hour is $\mathrm{L}$ and is scheduled to be increased to $\mathrm{H}$ in the next two hours, the system overheats the building in the winter (increasing $T_{s}$ to $23^{\circ} \mathrm{C}$ ) or overcools during the summer (decreasing $T_{s}$ to $23^{\circ} \mathrm{C}$ ). Depending on load requirements, the HVAC system operates with variable power $p_{i}$. If the price of energy is $\mathrm{H}$, regardless of the current air temperature $T_{a}$, the HVAC system is deactivated $\left(p_{i}=0\right)$.

The total energy consumed by the HVAC system in a single day is calculated according to (5).

$\sum_{i=1}^{24} E_{i}^{d}=\sum_{i=1}^{24} \int p_{i} d t$

where: $E_{i}^{d}$ is energy consumed by HVAC system, $p_{i}$ is heating/cooling load, $t$ is time (h).

\section{Building as a part of energy system}

\subsection{Present and future trends in the building energy market}

Buildings are responsible for around $40 \%$ of energy consumption in well developed countries like EU member states, USA or Canada. The general energy share at the operational stage are usually the highest taking into account the total building life cycles but certainly depends on a building standard. The energy cost varies between regions and depends on economic factors, availability of energy sources, energy efficiency standards and local climate. Also for old, not modernized buildings the cost will be much higher than for new - low, passive or even near zero energy buildings. In severe climatic conditions the heating energy dominates in energy balance, while in warmer location a cooling energy is essential. Buildings located in moderate climatic conditions require keeping stable indoor conditions during almost the whole year and are characterized by both heating and cooling energy consumption at a similar level.

The new tendency and requirements in building energy performance prefer the design and development of buildings with a relatively low, nearly (nZEB) or even zero-energy balance (ZEB) [34, 35], when renewable energy sources are using on-site. The current basic energy requirements imposed to minimize heat exchange processes by conduction and an air flow between a building and external environment as well as controlled solar heat gains. The main strategy to limit heat losses through transmission is improving thermal insulation of the building envelope. The present heat transmission coefficient for nearly zero energy building has become lower and lower, often achieving economically unjustified values. In EU countries the average thermal transmission for new buildings are respectively, walls $0.29 \mathrm{~W} / \mathrm{m}^{2} \mathrm{~K}$ (range: $0.065-1.97 \mathrm{~W} /$ $\mathrm{m}^{2} \mathrm{~K}$ ), windows $1.16 \mathrm{~W} / \mathrm{m}^{2} \mathrm{~K}$ (range: $0.70-4.5 \mathrm{~W} / \mathrm{m}^{2} \mathrm{~K}$ ), roofs $0.14 \mathrm{~W} / \mathrm{m}^{2} \mathrm{~K}$ (range: $0.06-0.55 \mathrm{~W} / \mathrm{m}^{2} \mathrm{~K}$ ) and ground floors $0.29 \mathrm{~W} / \mathrm{m}^{2} \mathrm{~K}$ (range: $0.068-2.19 \mathrm{~W} / \mathrm{m}^{2} \mathrm{~K}$ ) [36]. There are also some effective strategies to minimize ventilation heat losses by application of heat recovery from exhausted air or preheating in a ground-coupled heat exchanger with simultaneous increased air tightness of building envelope. It means that traditional, non-mechanical ventilation is less and less often used in practice what will certainly provide limitation and controlling of heat exchange by ventilation in a new and modernized buildings. According to the data provided in [36], about three quarters of the nearly zero energy buildings use a mechanical ventilation system with heat recovery. Only three of the buildings in the report [37] rely on natural ventilation (window opening) for fresh air.

On the other hand there is a huge potential to apply renewable sources of heating or electricity supply in nearly zero energy buildings. In many countries different types of heat pumps and solar collectors are justified for heating and hot water production, but it should be also 
considered that both systems requires supplementary electric power. The price of electricity and production technology can determine only the slight economic and environmental effect of such solution. It should be noted that some countries produce power from renewable energy sources like wind (e.g. Denmark), solar (e.g. Germany) or hydro power stations (e.g. Norway). In terms of averaged renewable energy produced on-site, PV panels are the most common option, with nearly $70 \%$ of the nZEB examples using them. Solar thermal panels are a part of the energy concept in more than half of the buildings. Other renewable energy used in the buildings is geothermal (from ground source heat pumps), biomass and district heating with high shares of renewable energy. On the opposite side in some EU countries the main fossil fuel for electricity production is coal (e.g. Poland). These facts will determine the final definition of a zero-energy or zero-emission building in different countries and regions, but what we can be sure is that delivered energy is still going to be minimized. Additionally, concerning application of more advanced heat production like heat pumps or mechanical ventilation with heat recovery and preheated systems causes that main source of heating/cooling energy becomes electricity. It means that the number of new developed, low energy buildings mainly supplied by electrical energy will grow up, rising a share in building electricity balance and finally influencing on an energy market.

Based on the case studies data provided in [36] for the nZEB a wide range of building envelope qualities and types of building service systems including RES were determined. The most dominant technologies are: increased insulation thickness and application of high performance windows, as well as mechanical ventilation systems with heat recovery, heat pumps and PV applications. Also because there are differences between climatic conditions, some of the solutions are less frequently adopted in southern EU countries. Following this tendency it means that electricity share in a total energy consumption for new, energy efficient buildings is higher than for others built in a past. Taking into account this specific characteristics of building performance it is worth to consider new method to decrease energy consumption and energy cost by building energy management systems application which is demand-side management [38]. This method will be particularly valuable in the case when the power distributors put tariffs into practice with volatile energy prices and the buildings and systems will allow the shifting of energy peaks during the day and night.

\subsection{Energy performance and dynamics of building and system}

The overall energy usage in a building is determined by heating, cooling, domestic hot water, auxiliary systems and domestic appliances. Ventilation need is related to HVAC systems and included in heating or cooling. Considering the daily profile of energy demand, heating/cooling and hot water is powered by auxiliary systems. It means that the daily changes in power for auxiliary systems are coincident with heating/cooling and hot water respectively. Domestic appliances as a washing machine or a dishwasher have different power profiles dependent on user habits, e.g. doing washing every Monday afternoon or using a dishwasher just after a dinner. Considering thermal energy storage of the elements of building it seems to be justified that the potential of structural thermal mass can help in reduction of peak load both for heating and cooling.

The daily distribution of power for heating and cooling (including auxiliary energy) can be determined by the occupancy profile and building dynamics together with its energy performance and local climatic conditions. Intermitted heating/cooling combined with thermal mass can be also utilized for shifting maximum energy demand during the day. On the other hand any variations between continuous and intermittent (reduced or even shut-down) heating/cooling could not disturb the required indoor comfort conditions.

The effect of temperature changes while the building is being naturally cooled after switching off the heating system is presented in Fig. 9. The dynamic characteristic of the building can be determined by relative changes in indoor air resultant temperature determined by:

$\Delta T_{r e l}=T_{0}^{\prime}+\exp ^{-k t}$

where $T_{0}^{\prime}$ - the initial indoor resultant temperature calculated as an averaged value of air temperature and mean radiant temperature of surrounding surfaces, expressed by:

$T_{0}^{\prime}=0.5\left(T_{m r t}^{\prime}+T_{a}^{\prime}\right)$,

where $T_{a}^{\prime}-$ the initial indoor air temperature, $T_{m r t}^{\prime}-$ the initial mean radiant temperature, expressed by:

$T^{\prime}{ }_{m r t}=\frac{\sum_{i=1}^{n} T_{s i}^{\prime} \varepsilon_{i} A_{i}}{\sum_{i=1}^{n} A_{i}}$

where $T_{s}$ - the surface temperature, $k$ - coefficient of building thermal performance, $t$ - time. 


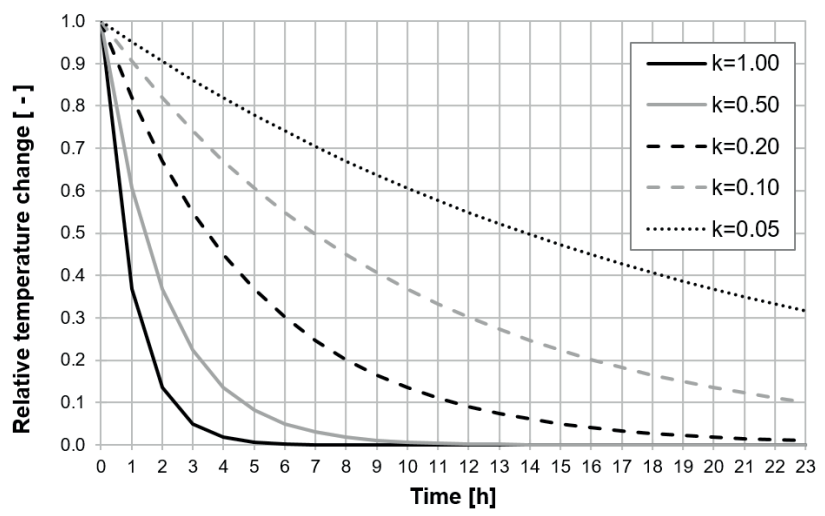

Fig. 9 Relative temperature change when the heating/cooling system is turned off

The thermal dynamic of a building is determined by both gain and loss heat fluxes. The sources of heat gains are usually specified by solar radiation fluxes through external transparent elements and internal heat fluxes from occupants, lighting and equipment. Heat loss, by transmission and ventilation [39], depends on building characteristics and temperature differences between internal and external environment [40]. Additionally, any lag in temperature changes is determined by thermal inertia of a building itself [41]. The coefficient $k$ proposed in (6) accounted both fluxes mentioned above, that is heat gains and losses.

The analogical line of thought could be specified for building under summer conditions where cooling system is turned off. The additional sources of heat gains are minimized by heat lost, but leads to building overheating. Thermal inertia of a building construction determines the time when indoor temperature achieved external one. In many specific cases, when heat gain are much higher than heat loss the indoor temperature can even exceed external temperature.

Thermal energy storage (TES) technologies that are applied in building fabric are widely described in literature, e.g. [42, 43]. Generally, TES can be classified into three categories: sensible, latent and thermochemical systems [44], but a thermochemical system is nowadays poorly compatible with building structure. The storage methods in these categories can be grouped into a short-term storage (hourly, daily) and a long-term storage (seasonal, yearly), however the construction elements usually played a role of daily, short term storage systems. The potential of sensible storage is characteristic for all building components with high heat capacity as a product of density $\rho$ and specific heat $C_{p}[22]$. On the other hand it is possible to increase storage potential by application of PCM as a latent heat $C_{l}$ [45] especially in construction elements [46]. Both approaches can be adopted for internal parts and building envelope which should be additionally sufficiently insulated. The effect of positioning of thermal mass in external walls was considered theoretically and discussed by Heim \& Wieprzkowicz [47]. In some specific cases thermal mass can even allow to achieve building thermal autonomy caused by efficient accumulation of heat gains [48].

For the purpose of current study the effect of thermal energy storage in building construction is considered in a context of DSM [49]. The authors reviewed TES technologies, their application for DSM purposes and existing experiences [49]. The techniques how to thermally activate a building by integration of heating/cooling system devices in the building structure was presented in $[50,51]$. As a result the building elements act as thermal storage and have an active role in the energy supply and demand management. Results presented in [52] show that the use of the structural storage capacity in buildings is able to significantly reduce the heat pump electricity usage during peak demand periods. Moreover, the DSM potential is higher for the massive buildings compared to the lightweight buildings. Additionally, authors noted that activating the thermal mass demands for active control of the indoor temperature and is therefore limited by thermal comfort requirements and also increases the total energy use. This increased energy usage needs to be balanced by efficiency gains at building or network level to make DSM using the structural storage profitable also from an energy point of view.

\section{Building performance - modelling and simulation 5.1 Methodology}

An analysis of a real building energy characteristic is a complex issue, requires advanced numerical methods and properly defined boundary conditions [53, 54]. The several computer software like ESP-r, Energy Plus or TRNSYS meet this criteria by application of dynamic wmodels of building as an integrated physical system with common interaction between thermal (sensible and latent), electrical and mechanical energy balance [55].

The prediction of a thermal load and building performance were determined using a numerical method of heat transfer and transient conduction. Numerical methods treat the building envelope surface as being made of discrete capacitances and resistances as this can be seen most clearly in the derivation of the finite volume method [54]. In the building model used for the purpose of simulation the walls as well as other elements are modelled in one-dimension, using a default value of three discrete capacitances per layer. 
Table 2 Wall construction for heavy and light mass type

\begin{tabular}{|c|c|c|c|c|c|}
\hline $\begin{array}{l}\text { Wall } \\
\text { type }\end{array}$ & Material & $\begin{array}{c}\mathrm{d} \\
{[\mathrm{m}]}\end{array}$ & $\begin{array}{c}\lambda \\
{[\mathrm{W} /(\mathrm{mK})]}\end{array}$ & $\begin{array}{c}\mathrm{r} \\
{\left[\mathrm{kg} / \mathrm{m}^{3}\right]}\end{array}$ & $\begin{array}{c}\mathrm{c}_{\mathrm{p}} \\
{[\mathrm{J} /(\mathrm{kgK})]}\end{array}$ \\
\hline \multirow{4}{*}{$\underset{\mathbb{J}}{\stackrel{\vec{J}}{*}}$} & Plaster & 0.015 & 0.820 & 1850 & 840 \\
\hline & Concrete & 0.250 & 1.700 & 2500 & 840 \\
\hline & Polystyrene & 0.450 & 0.036 & 30 & 1460 \\
\hline & Plaster & 0.005 & 0.820 & 1850 & 840 \\
\hline \multirow{3}{*}{$\begin{array}{l}\text { Е. } \\
.000 \\
ت\end{array}$} & Gypsum & 0.012 & 0.230 & 1000 & 1000 \\
\hline & Min. wool & 0.450 & 0.036 & 120 & 750 \\
\hline & Wood sid. & 0.045 & 0.160 & 550 & 2510 \\
\hline
\end{tabular}

Table 3 Roof construction for heavy and light mass type

\begin{tabular}{|c|c|c|c|c|c|}
\hline $\begin{array}{l}\text { Roof } \\
\text { type }\end{array}$ & Material & $\begin{array}{c}\mathrm{d} \\
{[\mathrm{m}]}\end{array}$ & $\begin{array}{c}1 \\
{[\mathrm{~W} /(\mathrm{mK})]}\end{array}$ & $\begin{array}{c}\mathrm{r} \\
{\left[\mathrm{kg} / \mathrm{m}^{3}\right]}\end{array}$ & $\begin{array}{c}\mathrm{c}_{\mathrm{p}} \\
{[\mathrm{J} /(\mathrm{kgK})]}\end{array}$ \\
\hline \multirow{5}{*}{$\underset{\mathbb{J}}{\stackrel{\mathbb{J}}{\mathbb{J}}}$} & Plaster & 0.015 & 0.820 & 1850 & 840 \\
\hline & Concrete & 0.360 & 1.700 & 2500 & 840 \\
\hline & Min. wool & 0.500 & 0.300 & 120 & 750 \\
\hline & Wood boar. & 0.025 & 0.160 & 550 & 2510 \\
\hline & Bit. tiles & 0.007 & 0.180 & 1000 & 1450 \\
\hline \multirow{4}{*}{ t. } & Gypsum & 0.012 & 0.230 & 1000 & 1000 \\
\hline & Min. wool & 0.500 & 0.300 & 120 & 750 \\
\hline & Wood boar. & 0.025 & 0.160 & 550 & 2510 \\
\hline & Bit. tiles & 0.007 & 0.180 & 1000 & 1450 \\
\hline
\end{tabular}

For an analysis of building thermal behaviour as well as energy performance and comfort metrics an integrated simulation system ESP-r was used. ESP-r is a well-known simulation environment for dynamic analysis of a building and system including control strategies, occupant comfort, renewable energy systems, etc. The building model is determined by physical properties of construction elements and occupancy profiles including ventilation rate and internal heat gains. The thermal characteristics of partitions is defined by the basic physical properties e.g. conductivity, density and specific heat of individual materials. Furthermore, this thermal characteristic effects on a building energy performance (energy demand and thermal comfort), depended on many different factors i.e.: heat gains and losses, user behaviour, thermal inertia etc. The system (e.g. HVAC) characteristic depends on plant equipment and control strategy determined by user schedule and comfort requirements.

\subsection{Building model}

Two types of single family houses were considered as the case study for the purpose of this work. Both meet the criteria of extremely low energy buildings under moderate climatic conditions. The floor area of $180 \mathrm{~m}^{2}$ is also the same in both cases. Physical building models developed in an ESP-r consist of construction (materials) characteristic of selected internal and external partitions. Both considered cases, heavy (HC) and light (LC), differ in construction types what is represented by the overall thermal mass. The materials used in a model of the analysed buildings and theirs physical properties were compared in Table 2 (for walls) and 3 (for roofs), order from inside to outside of the building. The heat capacity for the inner $5 \mathrm{~cm}$ layer of the wall is $97 \mathrm{~kJ} / \mathrm{m}^{2} \mathrm{~K}$ for heavy wall what is around 6.5 times higher than for light wall $\left(15 \mathrm{~kJ} / \mathrm{m}^{2} \mathrm{~K}\right)$. The similar heat capacity was obtained for both roofs construction. More detailed data was displayed in Table 3. Also internal partitions differ between heavy and light construction types in the same way.

All windows in both types of buildings were assumed to be a triple glazed with total $\mathrm{U}$ value $0.70 \mathrm{~W} /\left(\mathrm{m}^{2} \mathrm{~K}\right)$. The total windows area of $40 \mathrm{~m}^{2}$ were spread among four elevations in the following ratio: S-37.5 \%, E\&W-25\%, $\mathrm{N}-12.5 \%$. Additionally, all windows were equipped with a venetian blind system, which is activated when indoor air temperature exceeds $23^{\circ} \mathrm{C}$ to protect overheating.

The operations of a HVAC system as well as daily profiles of internal heat gains are results of building occupancy and controls of plant components. It was assumed that a building is occupied 24 hours per day, mechanically ventilated with heat recovery at a constant level of air changes per hour. Internal heat gains were assumed during the whole day. Based on the assumptions and objectives of the algorithm developed and presented in the Section 3.2 the author proposed three different HVAC control cases. For the further analysis of energy demand and costs as well as thermal comfort three following cases were considered:

Case 1 - continuous heating/cooling;

Case 2 - intermittent heating/cooling in the period of the highest energy price (HP),

Case 3 - intermittent heating/cooling in the period of the highest energy price (HP) and overheating/overcooling in the period of the lowest energy price (LP).

The daily profiles for three cases are presented in Table 4 (winter) and 5 (summer). NC means that the building in not conditioned, the HVAC system is turned off. The Case 3 is the original TEMS control algorithm.

It was assumed for the Case 1 that the minimum and maximum temperatures in the analysed buildings were controlled by the system and kept within the range of $20-26^{\circ} \mathrm{C}$ which means that the indoor conditions are not stable but are controlled. In the $2^{\text {nd }}$ case, the air temperature in buildings 
Table 4 Indoor air temperature $(T)$ set point for winter period

\begin{tabular}{lccc}
\hline hour & Case 1 & Case 2 & Case 3 \\
\hline 00:00-14:00 & $T_{a} \geq 20^{\circ} \mathrm{C}$ & $T_{a} \geq 20^{\circ} \mathrm{C}$ & $T_{a} \geq 20^{\circ} \mathrm{C}$ \\
14:00-16:00 & & $T_{a} \geq 23^{\circ} \mathrm{C}$ \\
16:00-19:00 & & $\mathrm{NC}$ & $\mathrm{NC}$ \\
19:00-00:00 & & $T_{a} \geq 20^{\circ} \mathrm{C}$ & $T_{a} \geq 20^{\circ} \mathrm{C}$ \\
\hline
\end{tabular}

Table 5 Indoor air temperature $\left(T_{a}\right)$ set point for summer period

\begin{tabular}{lccc}
\hline hour & Case 1 & Case 2 & Case 3 \\
\hline 00:00-09:00 & $T_{a} \leq 26^{\circ} \mathrm{C}$ & $T_{a} \leq 26^{\circ} \mathrm{C}$ & $T_{a} \leq 26^{\circ} \mathrm{C}$ \\
09:00-11:00 & & $T_{a} \leq 23^{\circ} \mathrm{C}$ \\
11:00-14:00 & & $\mathrm{NC}$ & $\mathrm{NC}$ \\
14:00-00:00 & & $T_{a} \leq 26^{\circ} \mathrm{C}$ & $T_{a} \leq 26^{\circ} \mathrm{C}$ \\
\hline
\end{tabular}

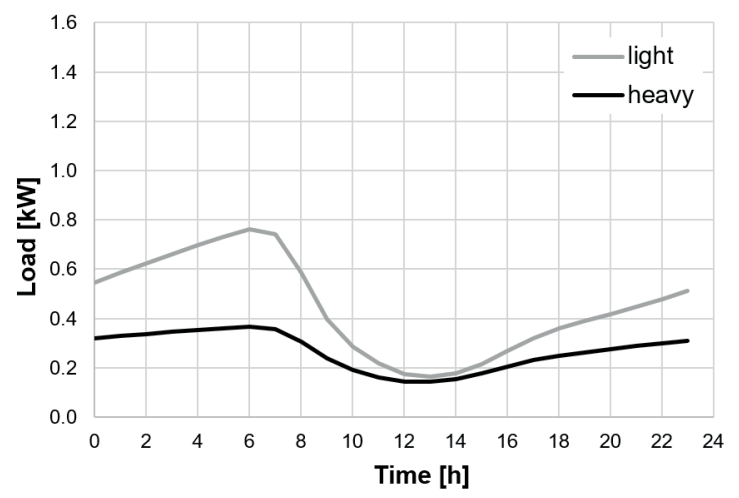

Fig. 10 Heating load for the Case 1

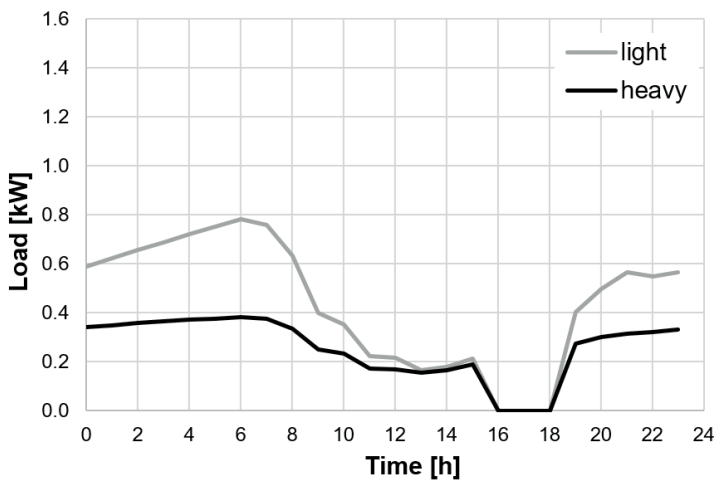

Fig. 11 Heating load for the Case 2

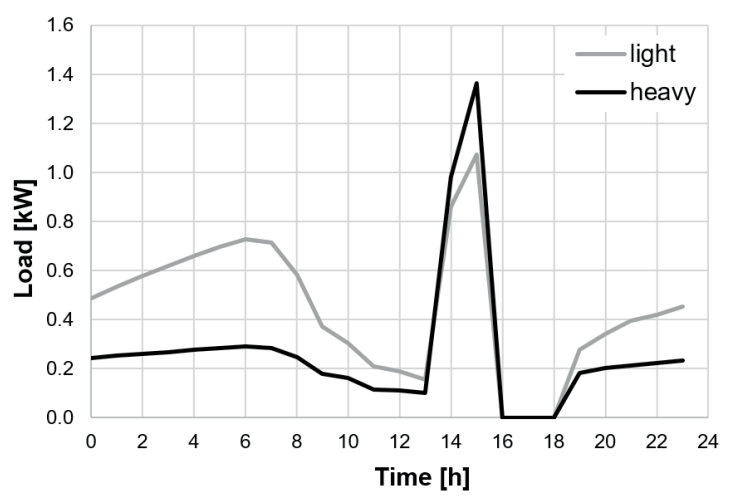

Fig. 12 Heating load for the Case 3 can be out of this range $\left(20-26^{\circ} \mathrm{C}\right)$ in a period of the highest electricity price but is partly stabilized by thermal inertia of building construction. In the Case 3, building thermal mass was additionally used as energy storage which is loaded during two hours before peak price, always just in a period of the lowest fee by overheating (winter) or overcooling (summer) of the building up/down to $23^{\circ} \mathrm{C}$. After that period, during next 3 hours the air temperature in buildings can be out of the range of $20-26^{\circ} \mathrm{C}$ again.

Simulations were carried out for a typical meteorological year (TMY), developed for the specific location of the city located in central Poland, Central Europe (51 ${ }^{\circ} 46 \mathrm{~N}$; $19^{\circ} 27$ E) characterized by moderate climatic conditions. The heating season is usually slightly longer in comparison to the cooling one. The weather file of the TMY used in the simulation was developed basing on the real weather data recorded at a meteorological weather station from 1970 to 2000 year. This TMY file has been officially approved as a weather file for building performance analysis. The minimum outdoor dry-bulb temperature occurs in January $\left(-12.5^{\circ} \mathrm{C}\right)$, while the maximum is in July $\left(34.3^{\circ} \mathrm{C}\right)$. The yearly average temperature is $8.2^{\circ} \mathrm{C}$. Diffused solar radiation is dominant during the whole year.

The initial simulation results obtained for numerical models of two types of buildings ( $\mathrm{HC}$ and LC) confirmed that power profiles can be arranged in three period types according to a time of the year. These periods are coincident with the periods obtained from analysis of power system demand (Section 3.1). Therefore, the three following periods were determined for further investigations:

- winter period (January, February, November and December) with heating energy demand,

- spring/autumn (March, April, September and October) with negligible energy demands for heating and cooling,

- summer period (from May to August) with cooling energy demand.

\subsection{Results of the building power demand simulation}

The simulation was conducted for the whole year with a one hour time-step. Two types of building were considered: heavy (HC) and light (LC) weight construction, which thermophysical properties were determined in 5.2. Based on the detailed results the average daily profiles for summer and winter were worked out using hourly data. In the further analysis only winter and summer period were considered. The profiles are presented in Figs. 10-12 and Figs. 13-15. 


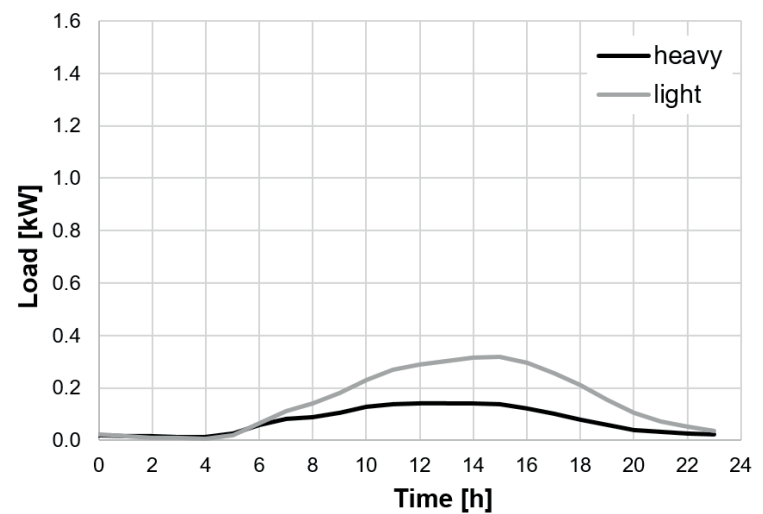

Fig. 13 Cooling load for the Case 1

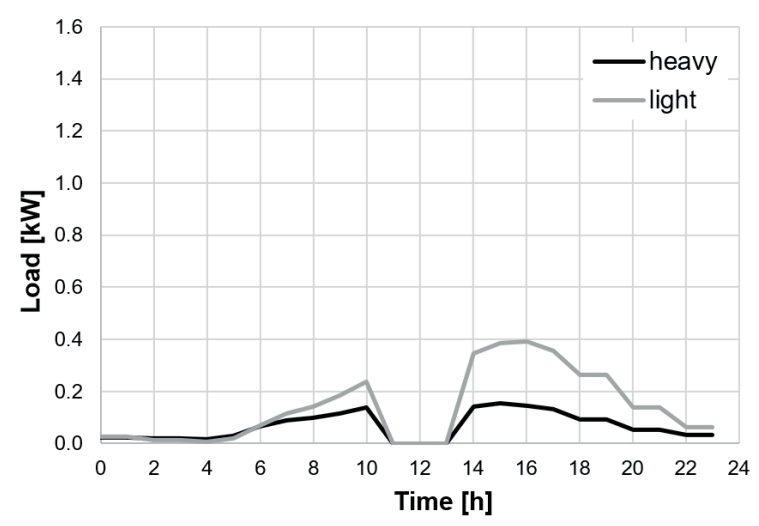

Fig. 14 Cooling load for the Case 2

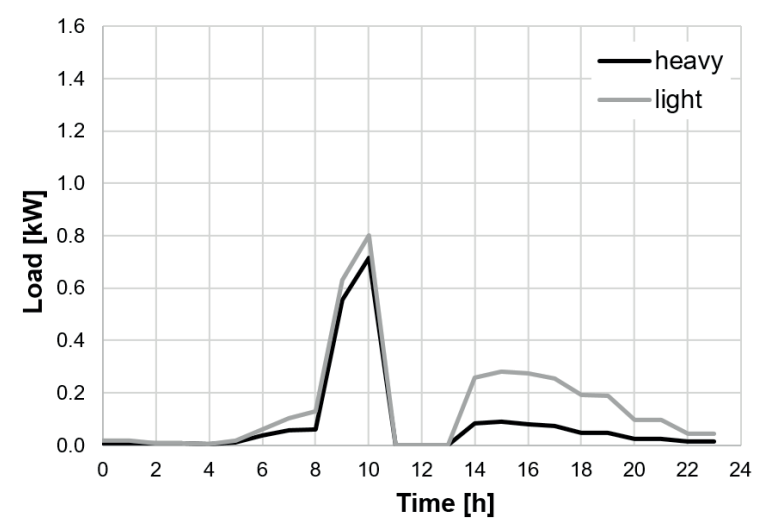

Fig. 15 Cooling load for the Case 3

\section{Building performance and energy cost}

\subsection{Energy consumption}

It has been assumed that in a winter period the HVAC system consumes energy only for heating, and in a summer period only for cooling. Due to good thermophysical properties of a building envelope as well as heat recovery from a ventilation system and opportunity of passive cooling and heating, energy consumption of the HVAC system in spring/autumn period was negligible $(<2 \%)$. The Table 6 shows calculated annual energy demand based on the one hour time-step dynamic simulation for three control cases (LC and $\mathrm{HC}$ buildings).
Table 6 Energy demand of the HWAC system in the LC and HC building

\begin{tabular}{lccc}
\hline $\begin{array}{c}\text { Type of } \\
\text { building }\end{array}$ & Case of control HVAC & $\begin{array}{c}\text { Winter period } \\
(\mathrm{kWh})\end{array}$ & $\begin{array}{c}\text { Summer period } \\
(\mathrm{kWh})\end{array}$ \\
\hline \multirow{3}{*}{$\mathrm{LC}$} & Case 1 & 1276 & 430 \\
& Case 2 & 1269 & 417 \\
& Case 3 & 1302 & 464 \\
$\mathrm{HC}$ & Case 1 & 754 & 214 \\
& Case 2 & 743 & 203 \\
& Case 3 & 819 & 266 \\
\hline
\end{tabular}

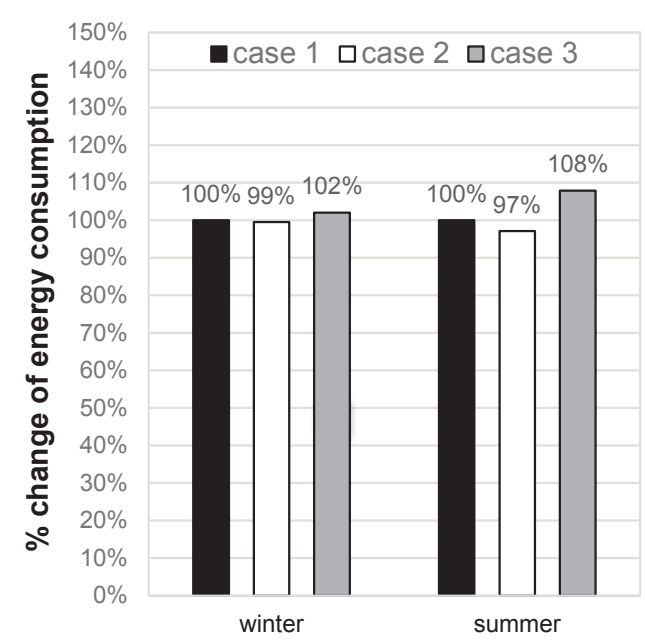

Fig. 16 Impact of system HVAC control cases on energy consumption for the LC building

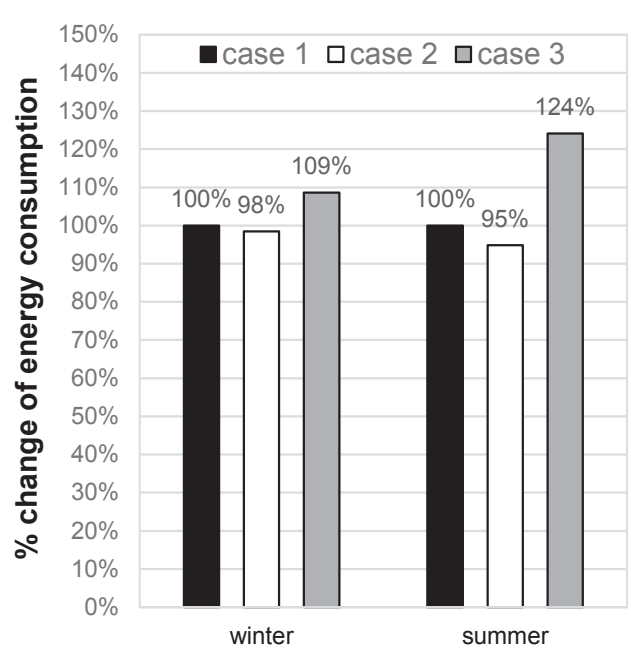

Fig. 17 Impact of system HVAC control cases on energy consumption for the $\mathrm{HC}$ building

Figs. 16 and 17 show percentage change of energy consumption for different control cases for the LC and HC building respectively. Energy of the building from the case 1 is a reference. Figures shows separation for winter and summer period. 


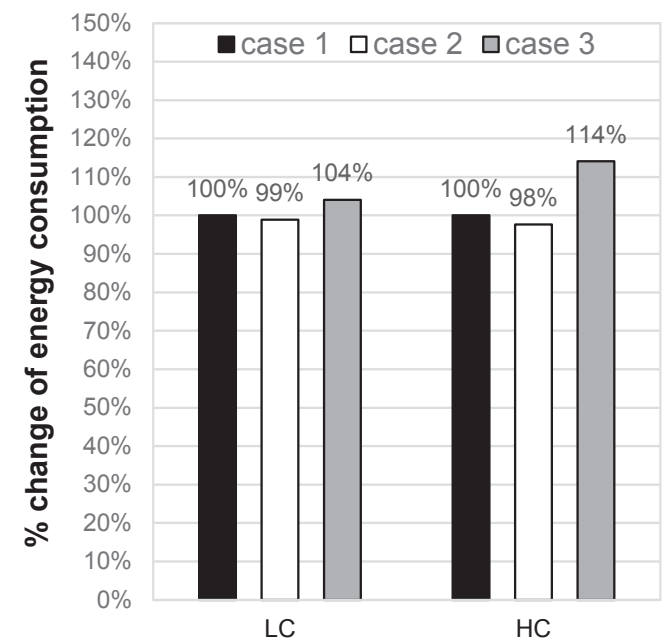

Fig. 18 Impact of system HVAC control cases on yearly energy consumption for the $\mathrm{LC}$ and $\mathrm{HC}$ building

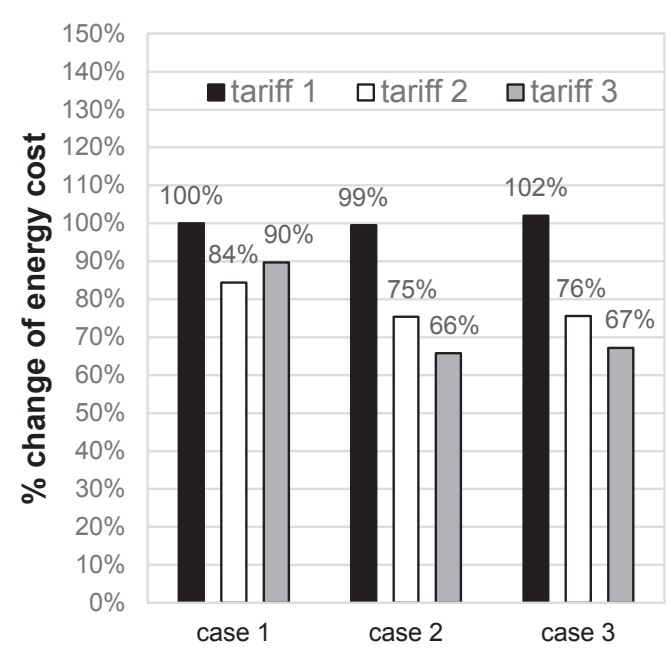

Fig. 19 The impact of tariffs on the cost of energy for the LC building during a winter period

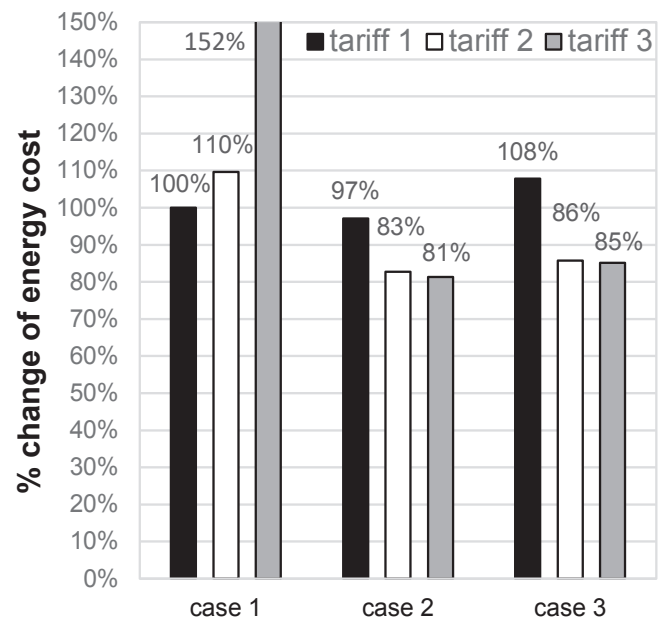

Fig. 20 The impact of tariffs on the cost of energy for the LC building during a summer period

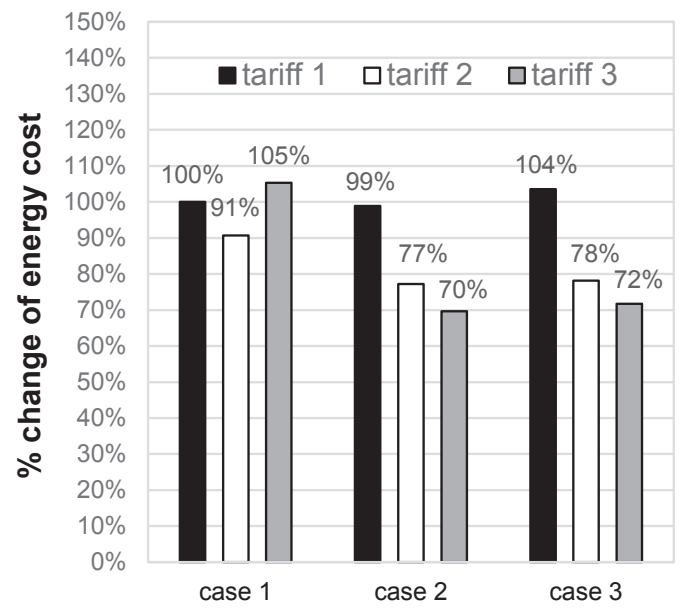

Fig. 21 The impact of tariffs on the cost of energy for the LC building during a whole year

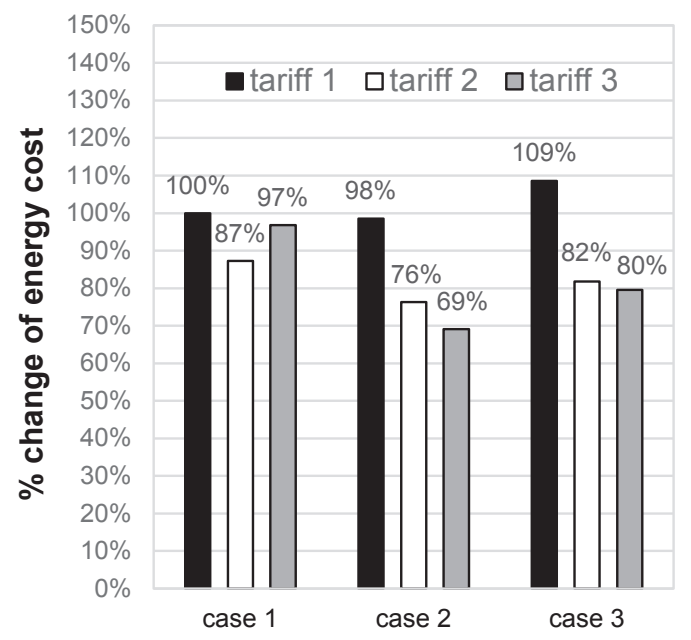

Fig. 22 The impact of tariffs on the cost of energy for the HC building during a winter period

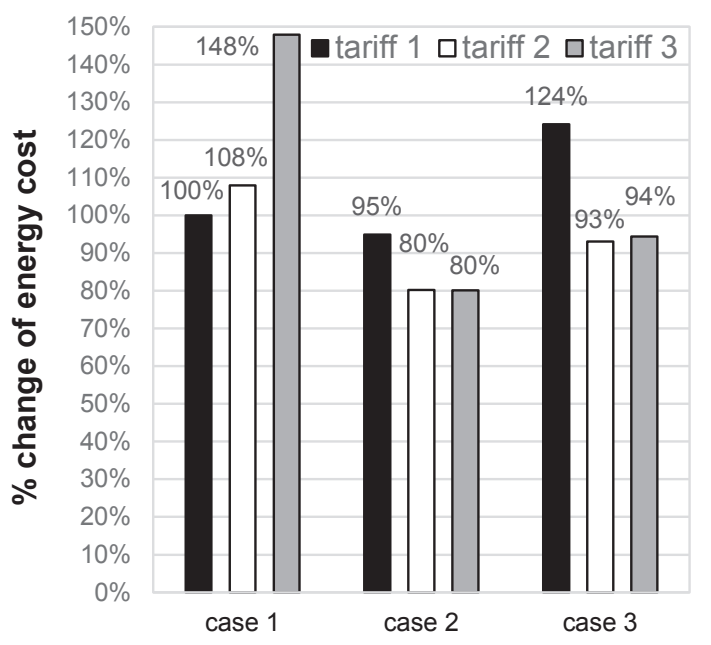

Fig. 23 The impact of tariffs on the cost of energy for the HC building during a summer period 
Table 7 Energy consumption in HP and LP periods for the LC and HC building

\begin{tabular}{|c|c|c|c|c|c|c|c|c|c|c|}
\hline & & \multicolumn{5}{|c|}{ Case 1} & \multicolumn{4}{|c|}{ Case 3} \\
\hline & & $\sum_{d=1}^{N} \sum_{i=1}^{24} E_{i}^{d}$ & $\sum_{d=1}^{N} E_{L P}^{d}$ & $\frac{\sum_{d=1}^{N} E_{L P}^{d}}{\sum_{d=1}^{N} \sum_{i=1}^{24} E_{i}^{d}}$ & $\sum_{d=1}^{N} E_{H P}^{d}$ & $\frac{\sum_{d=1}^{N} E_{H P}^{d}}{\sum_{d=1}^{N} \sum_{i=1}^{24} E_{i}^{d}}$ & $\sum_{d=1}^{N} \sum_{i=1}^{24} E_{i}^{d}$ & $\sum_{d=1}^{N} E_{L P}^{d}$ & $\frac{\sum_{d=1}^{N} E_{L P}^{d}}{\sum_{d=1}^{N} \sum_{i=1}^{24} E_{i}^{d}}$ & $\sum_{d=1}^{N} E_{H P}^{d}$ \\
\hline & & $(\mathrm{kWh})$ & $(\mathrm{kWh})$ & $(\%)$ & $(\mathrm{kWh})$ & $(\%)$ & $(\mathrm{kWh})$ & $(\mathrm{kWh})$ & $(\%)$ & $(\mathrm{kWh})$ \\
\hline \multirow{3}{*}{ LC } & summer & 430 & 51 & 12 & 106 & 25 & 464 & 176 & 38 & 0 \\
\hline & winter & 1276 & 46 & 4 & 112 & 9 & 1302 & 228 & 18 & 0 \\
\hline & total & 1706 & 97 & 6 & 218 & 13 & 1766 & 404 & 23 & 0 \\
\hline \multirow{3}{*}{$\mathrm{HC}$} & summer & 214 & 29 & 13 & 51 & 24 & 266 & 157 & 59 & 0 \\
\hline & winter & 754 & 39 & 5 & 80 & 11 & 819 & 278 & 34 & 0 \\
\hline & total & 968 & 67 & 7 & 132 & 14 & 1085 & 434 & 40 & 0 \\
\hline
\end{tabular}

$\mathrm{N}-$ the number of days in the period (winter: $\mathrm{N}=120$; summer: $\mathrm{N}=123$ )

Table 8 The rates in proposed tariffs

\begin{tabular}{cccc}
\hline Period & tariff 1 & tariff 2 & tariff 3 \\
\hline ,L” & $\mathrm{x}$ & $0.5 \mathrm{x}$ & $0.25 \mathrm{x}$ \\
„N" & $\mathrm{x}$ & $\mathrm{x}$ & $\mathrm{x}$ \\
,H” & $\mathrm{x}$ & $2 \mathrm{x}$ & $4 \mathrm{x}$ \\
\hline
\end{tabular}

$\mathrm{x}$ - price of energy in a basic tariff (a constant price for an entire day)

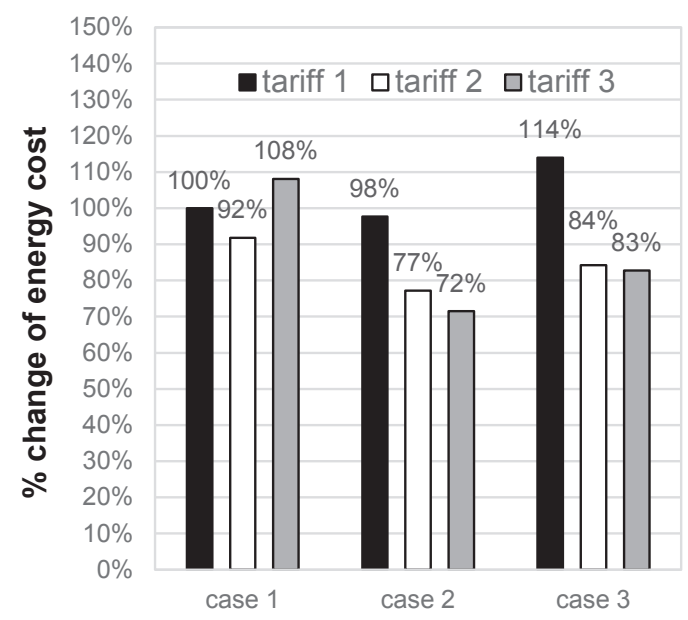

Fig. 24 The impact of tariffs on the cost of energy for the HC building during a whole year

The Case 2 very slightly lowers energy consumption in regard to the case 1 . For the LC building, implementation of the Case 3 causes increase of energy consumption by $2 \%$ and $8 \%$ for winter and summer period respectively. For HC building this growth was higher $(9 \%$ and $24 \%$ respectively). Fig. 18 shows impact of control cases of HVAC system on energy consumption in the LC building and the $\mathrm{HC}$ building during a whole year. Change of control scheme from 1 to 3 causes an increase of energy consumption by the HVAC system by $4 \%$ and $14 \%$ for the $\mathrm{LC}$ and $\mathrm{HC}$ building respectively.
Energy consumption shifting out of the peak zone (HP - high price period) was implemented in the Case 3. According to assumptions (Section 3.2) in this case, before peak zone the building was overheated (winter) or overcooled (summer). According to the Table 1 in both winter and summer periods, the peak zone was defined as a period of three hours. For a winter period it was from 16:00 to 19:00, and for a summer period it was from 11:00 to 14:00. The tariff proposed in the Table 1 has two hours of LP (a low price period) before an HP peak zone, in which cost of energy is reduced as a way to encourage consumers to shift energy consumption into this period. Table 7 shows aggregated energy consumption in HP and LP periods for the LC and HC building for summer and winter periods.

In the Case 1, energy consumption by HVAC system in HP period is twice as much as in LP period. This relation is fulfilled for both LC and HC buildings and for winter and summer period. It can be seen that regardless of the type of building, energy consumption during HP period was about 13-14 \%, and during LP period, about 6-7\% of total energy consumption. Using the developed control algorithm of the TEMS (Case 3) $23 \%$ and $40 \%$ of energy usage was moved on LP period for the LC and HC building respectively. Almost twice the difference results from the accumulation abilities of the HC building, which at low heat losses, drastically increase the rate of gains utilisation.

\subsection{Energy costs}

Based on analysis of a demand profile of the power system in Section 3.1 the schedule of a Time-of-Use (TOU) tariff was proposed. In order to estimate benefits of the selected tariff, there are three tariff cases adopted. Tariff 1 is a basic tariff in which price (basic price-x) for energy 
is constant for an entire day. Tariff 2 means energy for a half of basic price during the "L" period and a double of a basic price in the "H" period. Tariff 3 means 0.25 of a basic price during the "L" period and four times of a basic price in the "H" period. The Table 8 shows price lists in tariffs. Reference to the basic price allows to estimate relative benefits of the tariff change in relation to basic tariff.

Figs. 19-21 shows a percentage change of the energy cost for the LC building in relation to a binding tariff. An analogical graph for the $\mathrm{HC}$ building is shown on Figs. 22-24. Because the energy price in the tariff 1 is constant, the change of the cost of an energy purchase in this

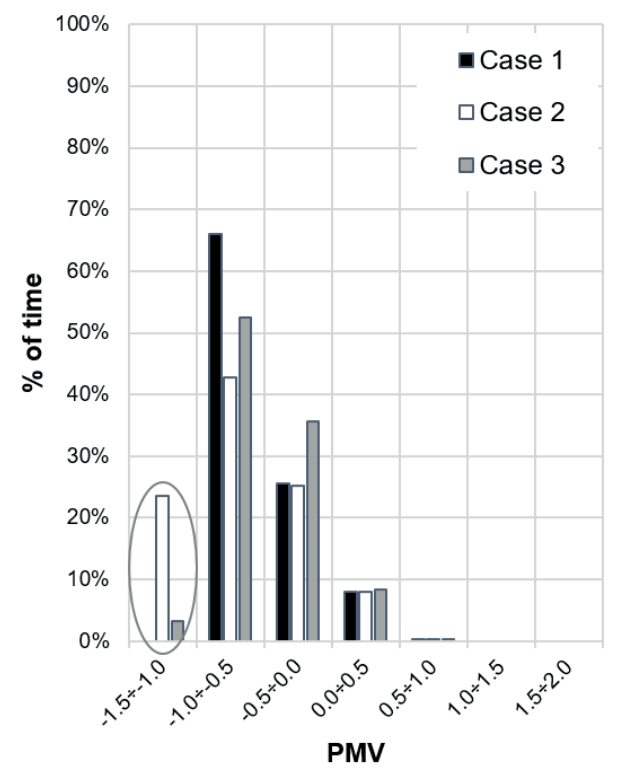

Fig. 25 PMV values for the winter period between 16:00 and 19:00 for the LC building

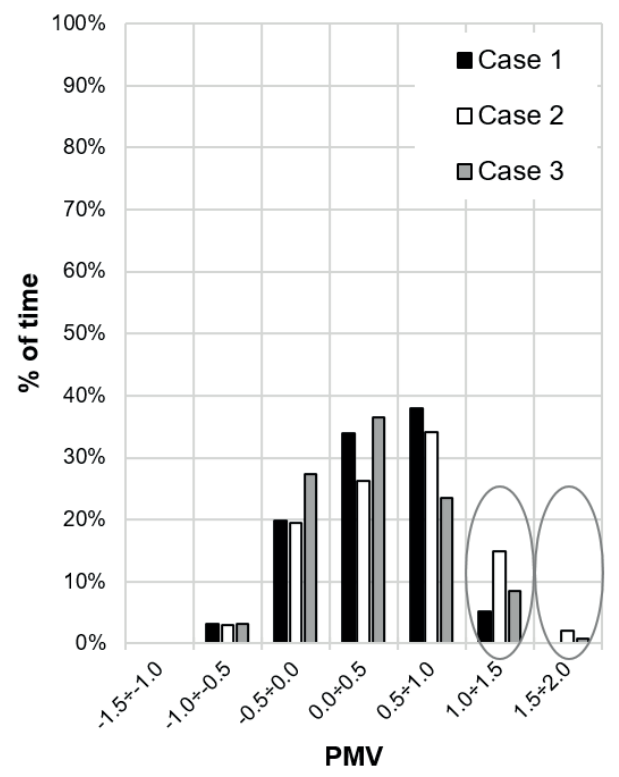

Fig. 27 PMV values for the summer period between 11:00 and 14:00 for the LC building tariff means the change of amount of consumed energy in each of analysed cases, which was described in section 6.1.

In a winter period for both types of buildings and in each control case of HVAC system, the cost of consumed energy is lower for the tariff 2 and 3 than for the tariff 1 . This differences are the smallest for the Case 1. For the case 3 , a cost of consumed energy decreases by about $24 \%$ in the tariff 2 and about $33 \%$ for the tariff 3 for the LC building. For the $\mathrm{HC}$ building savings for the Case 3 are smaller and cost decreases by $18 \%$ and $20 \%$ for tariffs 2 and 3 respectively. In a summer period the case 3 provide lesser savings. For the LC building those savings are about

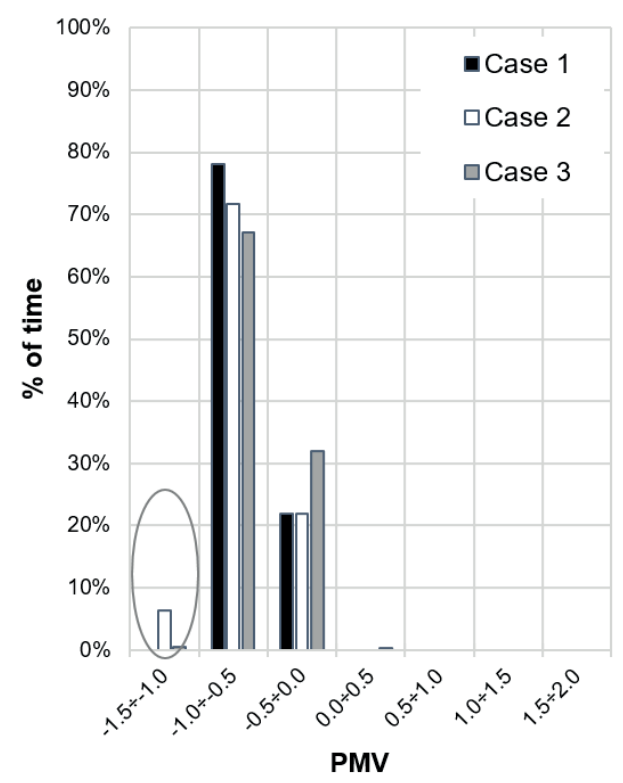

Fig. 26 PMV values for the winter period between 16:00 and 19:00 for the HC building

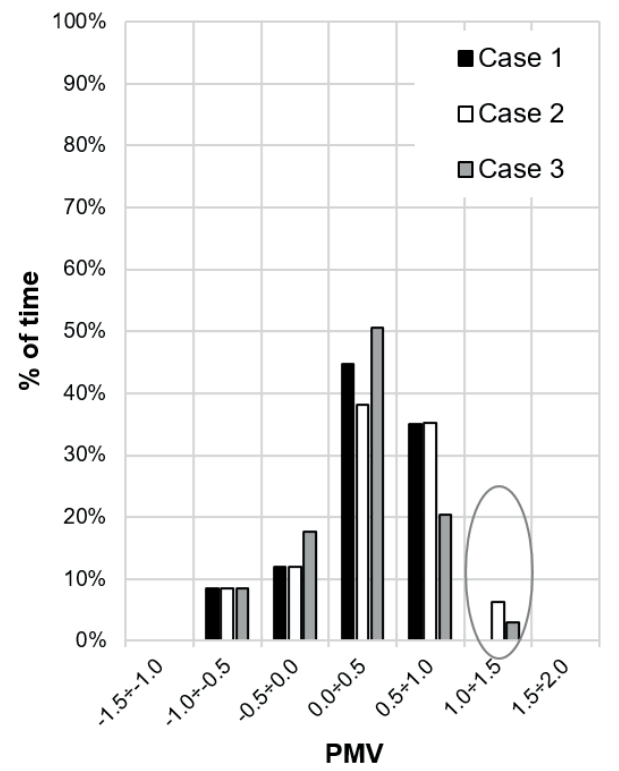

Fig. 28 PMV values for the summer period between 11:00 and 14:00 for the $\mathrm{HC}$ building 
$14-15 \%$, and for the HC building only 6-7\%. Significant growth of energy costs $(\sim 50 \%)$ occurs in a summer period for tariff 3 and the case 1 of the HVAC control system scheme. In terms of the whole year, for the LC building there are possible savings about 22-28\% depending on a tariff and a control case. For the HC building, savings in the Case 3 are smaller and they are about $16-17 \%$.

\subsection{Thermal comfort}

Thermal comfort was assessed using Predicted Mean Vote (PMV) index. PMV was calculated for each time step using variable environmental parameters $\left(T_{a}\right.$ and $\left.T_{m r t}\right)$ obtained from the ESP-r software [53].

Physiological variables like the metabolic rate $(M)$, as well as clothing surface factor $\left(f_{c l}\right)$ was determined independently. It was assumed that users have a sitting activity with Metabolic Equivalent of Task $M E T=1.0$, and $M=58.15 \mathrm{~W} / \mathrm{m}^{2}$. Clothing thermal insulation clo $(1$ clo $=$ $0.155 \mathrm{~m}^{2} \mathrm{~K} / \mathrm{W}$ ) was differentiated between summer and winter at the level of 0.35 (shorts, a short-sleeved shirt) and 0.70 (trousers, a long-sleeved shirt) respectively.

The obtained results were analysed statistically just in a period of intermittent heating/cooling - 3 hours per day. The PMV values from the period of controlled indoor condition meets the comfort criteria and were omitted.

Compiled results are presented in Figs. 25, 26 and Figs. 27, 28 for summer and winter periods respectively. For both, summer and winter periods a substantial difference was observed between different thermal mass buildings $\mathrm{HC}$ and LC. For the winter periods PMV varies between 0.5 and -1.5 , while for the summer between -1.0 and +2.0 . Additionally, for different control strategy cases there are different values of PMV during the whole year.

During the winter and continuous heating (Case 1) for both types of building constructions PMV values are in the comfort range from -1.0 to 1.0 , but dominant number of hours (above $60 \%$ ) is characterized by slightly cool conditions $(-1.0 \mid-0.5)$. Intermittent heating caused overcooling with PMV values up to -1.5 , however this effect is much smaller when the building construction is heavy ( $6 \%$ of total hours) than light ( $24 \%$ of total hours). Little building overheating (up to $23^{\circ} \mathrm{C}$ ) before the heating break allows avoiding indoor thermal conditions out of the comfort range.

A similar tendency is noticed for the summer period, when PMV values varies in the comfort range from -1.0 to 1.0, for heavy mass construction. The light building appears as slightly overheating due to the high solar radiation. Intermittent cooling gave the PMV values above 1.0, but heavy weight construction can reduce this effect more than twice, from $15 \%$ to $6 \%$ of hours. On the other hand the overcooling of the building before intermittent period (case 3) is not so substantial as for the winter period.

\section{Discussion}

Practically for each case of control in the LC building, in the winter period energy consumption of the heating system reached $75 \%$ of annual energy consumption of the HVAC system. Other $25 \%$ was used by an air conditioning system in the summer period. For the HC building this proportions changes slightly, causing reduction in total balance of energy share for heating to $70 \%$ with increase of energy used by an air conditioning system to $30 \%$. It confirms an effect of thermal inertia of different building construction and ability to store/release heat in a long term cycle.

Change of the control case from 1 to 3 , for both winter and summer periods, causes increase of energy consumption (Figs. 16, 17). For both LC and HC buildings, greater percentage increase occurs in the summer period. Change of HVAC system control scheme according to the control algorithm of TEMS (case 3 ) for the HC building resulting in a far greater increase in percentage of energy consumption than for the LC building. It is most visible in the summer period, when energy consumption is increased by $24 \%$. This phenomena is an effect of higher heat capacity and ability to store more energy in a period of summer overcooling from 9:00 to 11:00. In yearly balance the HC building with HVAC system (according to the original author's algorithm) consumes $14 \%$ more energy than as in the case 1. For the LC building this growth is about $4 \%$ (Fig. 18).

For the case 2 despite turning off HVAC system in period of the greater power usage, overall energy consumption is similar to the case 1 . This is due to the fact that shutdown of the HVAC system for a period of three hours resulting in overheating in the summer period and overcooling in the winter period, which in a turn results in that HVAC system works with greater power in next hours (Figs. 11, 14).

Twice as much energy consumption during the HP period than during the LP period with additional control scheme as in the case 1 is convergent with a current situation of the power grid system, which is shown in the section 2. Peak zones cause threats to the stability and security of the power grid system. Therefore, the goal is to develop mechanisms (for example TEMS), which will allow to shift the greatest demand to off-peak zones. According to results from the Table 7 buildings during both, winter and summer periods are using $25 \%$ of their 
total energy consumed by HVAC system, during the HP period. There is therefore a great potential to reduce peak demand. Because of existing infrastructure of objects and specific possibilities of selected users, it must be assumed that only a partial response demand, which will however secure the system from creating a new peak zone and provide distribution of energy demand evenly.

High costs of energy in summer period in tariff 3 for the control case 1 of the HVAC system indicates a wellmatched tariff, which could have strong influence on users. If consumers will apply TEMS then costs of consumed energy could be reduced by $15 \%$ with maintained thermal comfort. Lack of conscious energy management which is the issue in the case 1 will result in increase of costs by about $50 \%$. This is important considering a growing number of air conditioning systems installed in many buildings. The HC building uses less energy as the LC building but possibilities of obtaining measurable savings for a user are also twice as low as for the LC building.

Based on the analysis of thermal comfort obtained by a computer simulation it should be noted that adjusting work of heating system to prices in tariffs does not significantly affect PMV values. At the same time, as expected the HC building has better comfort parameters than the LC building, regardless of time of the year. In the winter period characterized by slight feeling of coolness, two hours of overheating the building (between 14:00 and 16:00) will allow maintaining comfortable conditions for another three hours (between 16:00 and 19:00), which is the period when most of household residents are in the building. At the same time the period of increased temperature is coincident with a period of solar heat gains. In the summer period, overcooling building from 9:00 to 11:00 is less justified because of significant heat gains in the period from 11:00 to 14:00 when a building is overheated due to downtime of cooling system.

\section{Conclusions}

Currently constructed buildings have low requirements for heat but high demand for electricity. In case of passive and nearly Zero Energy Buildings (nZEB), electricity is the only supply energy system. At the same time they are characterized by a significant ability to use temporary heat gains, shorter heating/cooling season and low power requirements.

Increase of renewable sources of energy and their less predictable and distributed energy generation often leads to surpluses of energy in grid, which is a significant problem for stability and safety of the system. Accordingly, the power system has a problem with energy availability at a given time, therefore the power availability. In this case, activation and participation of individual consumers on the energy market is crucial for the development of smart grids. One of the options of shifting peak power demand is using buildings as thermal energy storages.

In this article, analysis of power demand for the power system was made and on this base the control algorithm of TEMS was proposed. Its primary goal is an impact on energy consumers which will make a change of a demand power profile in order to limit energy consumption during a peak of power demand. Moreover, a model of controlling HVAC system for nZEB with different abilities to heat an energy storage was made. The performed analysis made it possible to revel potential energy cost savings while maintaining thermal comfort parameters and with costs reduction of peak power for the power system. On the basis of these results, following detailed conclusions was made.

The control algorithm described in this work (referred as a case 3 ) causes decreasing of energy consumption by HVAC system during peak hours and shifting power demand to hours when energy is less expensive. Applying this algorithm resulted in increase of energy consumption, regardless of heat capacity of a building. A modest (few percent) increase in energy consumption is not a significant problem for the power system because the real problem is the power availability. Despite increased energy consumption, according to different prices in a tariff, users have ability to reduce costs of heating/cooling a building. The developed algorithm allows to reduce energy costs without a significant loss of comfort parameters. User applying the developed control algorithm of TEMS (case 3) gains savings about 16-28 \%. On the other hand, lack of conscious supervision (case1) will result in an increase of energy costs by about $5-8 \%$ annually. This indicates a well-matched tariff and energy prices because a user would rather gain then lose and therefore the tariff will develop awareness of energy use among consumers. Two cases considered here extremely differs in thermal mass of the building. It means that for real building the expected results would be in the range of presented values.

From the point of view of producers, suppliers and sellers of energy the proposed control algorithm of TEMS, despite lower gains from sale of energy, gives significant benefits for the power system. Smaller profits from sale of energy are clearly compensated by decrease in:

- the costs of peak generating units as a result of the reduction of the maximum peak loads, 
- the transmission losses caused by the reduction in the maximum power transmitted by the grid,

- the costs of modernization of the infrastructure which is overloaded only during periods of peak power demand,

- the costs of maintaining the so-called "hot reserve"for the balance of power in the power system.

Increased energy consumption by consumers do not increase a consumption of primary energy. Reduced transmission losses, less overloaded infrastructure and reduction of maintenance of "hot reserve" units also reduces fossil fuels extraction and carbon dioxide emission.

\section{References}

[1] Qureshi, W. A., Nair, N.-K. C., Farid, M. M. "Impact of energy storage in buildings on electricity demand side management", Energy Conversion and Management, 52(5), pp. 2110-2120, 2011. https://doi.org/10.1016/j.enconman.2010.12.008

[2] Pérez-Lombard, L., Ortiz, J., Pout, C. "A review on buildings energy consumption information", Energy and Buildings, 40(3), pp. 394 398, 2008.

https://doi.org/10.1016/j.enbuild.2007.03.007

[3] Li, X., Bowers, C. P., Schnier, T. "Classification of Energy Consumption in Buildings with Outlier Detection", IEEE Transactions on Industrial Electronics, 57(11), pp. 3639-3644, 2009. https://doi.org/10.1109/TIE.2009.2027926

[4] Palensky, P., Dietrich, D. "Demand Side Management: Demand Response, Intelligent Energy Systems, and Smart Loads", IEEE Transactions on Industrial Informatics, 7(3), pp. 381-388, 2011. https://doi.org/10.1109/TII.2011.2158841

[5] Barr, S., Gilg, A. W., Ford, N. "The household energy gap: examining the divide between habitual- and purchase related conservation behaviours", Energy Policy, 33(11), pp. 1425-1444, 2005. https://doi.org/10.1016/j.enpol.2003.12.016

[6] Matsukawa, I. "The Effects of Information on Residential Demand for Electricity", The Energy Journal, 25(1), pp. 1-17, 2004. https://doi.org/10.5547/ISSN0195-6574-EJ-Vol25-No1-1

[7] Young, D. "When do energy-efficient appliances generate energy savings? Some evidence from Canada", Energy Policy, 36(1), pp. 34-46, 2008.

https://doi.org/10.1016/j.enpol.2007.09.011

[8] Allcott, H. "Social norms and energy conservation", Journal of Public Economics, 95(9-10), pp. 1082-1095, 2011. https://doi.org/10.1016/j.jpubeco.2011.03.003

[9] Jensen, C. L., Hansen, L. G., Fjordbak, T., Gudbjerg, E. "Providing Free Autopoweroff Plugs: Measuring the Effect on Households' Electricity Consumption through a Field Experiment", The Energy Journal, 33(4), pp. 187-211, 2012. https://doi.org/10.5547/01956574.33.4.9

[10] Gleerup, M., Larsen, A., Leth-Petersen, S., Togeby, M. "The Effect of Feedback by Text Message (SMS) and Email on Household Electricity Consumption: Experimental Evidence", The Energy Journal, 31(3), pp. 113-132, 2010. https://doi.org/10.5547/ISSN0195-6574-EJ-Vol31-No3-6
This analysis indicates potential in use of buildings as energy storage for the power system. Main goal of commercial energy management systems in buildings is a reduction of maintaining costs, while keeping users comfort at the same level and ensuring safety. The control algorithm of thermal energy management systems developed here not only strongly supports building integration with smart grid but also utilizes thermal potential of buildings for the benefit of the grid and energy consumers.

[11] Mills, B. F., Schleich, J. "Why don't households see the light?: Explaining the diffusion of compact fluorescent lamps", Resource and Energy Economics, 32(3), pp. 363-378, 2010.

https://doi.org/10.1016/j.reseneeco.2009.10.002

[12] Poortinga, W., Steg, L., Vlek, C., Wiesma, G. "Household preferences for energy-saving measures: A conjoint analysis", Journal of Economic Psychology, 24(1), pp. 49-64, 2003. https://doi.org/10.1016/S0167-4870(02)00154-X

[13] Centolella, P. "The integration of Price Responsive Demand into Regional Transmission Organization (RTO) wholesale power markets and system operations", Energy, 35(4), pp. 1568-1574, 2010. https://doi.org/10.1016/j.energy.2009.06.046

[14] Borkowski, P., Pawlowski, M. "Home/Building Management Systems (HMS/BMS) to Protect Environment by Control Modern Lighting Installations", In: 2nd International Conference on Chemical Engineering and Applications IPCBEE, Singapore, Republic of Singapore, 2011,pp. 141-145. [online] Availableat: http:// www.ipcbee.com/vol23/29-CCEA2011-M10020.pdf [Accessed: 25.03.2019]

[15] Pawłowski, M., Borkowski, P. "Electric Energy Management System in a Building with Energy Storage". Przeglad Elektrotechniczny, 88(12B), pp. 272-274, 2012. [online] Available at http://pe.org.pl/ articles/2012/12b/79.pdf [Accessed: 25.03.2019]

[16] Guzowski, B., Gozdur, R., Bernacki, L, Lakomski, M. "Investigations of DC power supplies with optoelectronic transducers and RF energy converters", Journal of Physics: Conference Series, 709, 2016. https://doi.org/10.1088/1742-6596/709/1/012008

[17] Shah, J. J., Nielsen, M. C., Shaffer, T. S., Fittro, R. L. "Cost-Optimal Consumption-Aware Electric Water Heating Via Thermal Storage Under Time-of-Use Pricing", IEEE Transactions on Smart Grid, 7(2), pp. 592-599, 2016. https://doi.org/10.1109/TSG.2015.2483502

[18] Du, P., Lu, N. "Appliance Commitment for Household Load Scheduling", IEEE Transactions on Smart Grid, 2(2), pp. 411-419, 2011.

https://doi.org/10.1109/TSG.2011.2140344

[19] Finn, P., O'Connell, M., Fitzpatrick, C. "Demand side management of a domestic dishwasher: Wind energy gains, financial savings and peak-time load reduction", Applied Energy, 101, pp. 678-685, 2013. https://doi.org/10.1016/j.apenergy.2012.07.004 
[20] Chen, C., Wang, J., Heo, Y., Kishore, S. "MPC-Based Appliance Scheduling for Residential Building Energy Management Controller", IEEE Transactions on Smart Grid, 4(3), pp. 1401-1410, 2013.

https://doi.org/10.1109/TSG.2013.2265239

[21] Wolisz, H., Harb, H., Matthes, P., Böse, L., Streblow, R., Müller, D. "The new role of night storage heaters in residential demand side management", In: Fifth German-Austrian IBPSA Conference: RWTH Aachen University, Aachen, Germany, 2014, pp. 611-616. [online] Available at http://www.ibpsa.org/proceedings/bausimPapers/2014/p1212_final.pdf [Accessed: 25.03.2019]

[22] Hasnain, S. M. "Review on sustainable thermal energy storage technologies. Part I. Heat storage materials and techniques", Energy Conversion and Management, 39(11) pp. 1127-1138, 1998. https://doi.org/10.1016/S0196-8904(98)00025-9

[23] Henze, G. P., Felsmann, C., Knabe, G. "Evaluation of optimal control for active and passive building thermal storage", International Journal of Thermal Sciences, 43(2), pp. 173-183, 2004. https://doi.org/10.1016/j.ijthermalsci.2003.06.001

[24] Heim, D. "Isothermal storage of solar energy in building construction", Renewable Energy, 35(4), pp. 788-796, 2010. https://doi.org/10.1016/j.renene.2009.09.005

[25] Pomianowski, M., Heiselberg, P., Zhang, Y. "Review of thermal energy storage technologies based on PCM application in buildings", Energy and Buildings, 67, pp. 56-69, 2013. https://doi.org/10.1016/j.enbuild.2013.08.006

[26] Cui, B., Wang, S., Yan, C., Xue, X. "Evaluation of a fast power demand response strategy using active and passive building cold storages for smart grid applications", Energy Conversion and Management, 102, pp. 227-238, 2015. https://doi.org/10.1016/j.enconman.2014.12.025

[27] Sun, Y., Wang, S., Xiao, F., Gao, D. "Peak load shifting control using different cold thermal energy storage facilities in commercial buildings: A review", Energy Conversion and Management, 71, pp. 101-114, 2013. https://doi.org/10.1016/j.enconman.2013.03.026

[28] Wolisz, H., Punkenburg, C., Streblow, R., Müller, D. "Feasibility and potential of thermal demand side management in residential buildings considering different developments in the German energy market", Energy Conversion and Management, 107, pp. 86-95, 2016.

https://doi.org/10.1016/j.enconman.2015.06.059

[29] Finn, P., Fitzpatrick, C. "Demand side management of industrial electricity consumption: Promoting the use of renewable energy through real-time pricing", Applied Energy, 113, pp. 11-21, 2014. https://doi.org/10.1016/j.apenergy.2013.07.003

[30] Pallonetto, F., Oxizidis, S., Milano, F., Finn, D. "The effect of timeof-use tariffs on the demand response flexibility of an all-electric smart-grid-ready dwelling", Energy and Buildings, 128, pp. 56-67, 2016.

https://doi.org/10.1016/j.enbuild.2016.06.041

[31] Khan, A. R., Mahmood, A., Safdar, A., Khan, Z. A., Khan, N. A. "Load forecasting, dynamic pricing and DSM in smart grid: A review", Renewable and Sustainable Energy Reviews, 54, pp. 13111322, 2016.

https://doi.org/10.1016/j.rser.2015.10.117
[32] Dan, D., Tanasa, C., Stoian, V., Brata, S., Stoian, D., Nagy Gyorgy, T., Florut, S. C. "Passive house design - An efficient solution for residential buildings in Romania", Energy for Sustainable Development, 32, pp. 99-109, 2016.

https://doi.org/10.1016/j.esd.2016.03.007

[33] Wu, M. H., Ng, T. S., Skitmore, M. R. "Sustainable building envelope design by considering energy cost and occupant satisfaction", Energy for Sustainable Development, 31, pp. 118-129, 2016. https://doi.org/10.1016/j.esd.2015.12.003

[34] Kolokotsa, D., Rovas, D., Kosmatopoulos, E., Kalaitzakis, K. "A roadmap towards intelligent net zero- and positive-energy buildings", Solar Energy, 85(12), pp. 3067-3084, 2011. https://doi.org/10.1016/j.solener.2010.09.001

[35] Sartori, I., Napolitano, A., Voss, K. "Net zero energy buildings: A consistent definition framework", Energy and Buildings, 48, pp. 220-232, 2012. https://doi.org/10.1016/j.enbuild.2012.01.032

[36] Maldonado, E. (Ed.) "2016 - Implementing the Energy Performance of Buildings Directive (EPBD)", Concerted Action EPBD, Adene, Lisbon, Portugal, 2016. [online] Available at http://www.epbd-ca. eu/outcomes/2011-2015/CA3-BOOK-2016-A-web.pdf [Accessed: 22.03.2019]

[37] Erhorn, H., Erhorn-Kluttig, H. "Selected Examples of Nearly Zero Energy Buildings", Concerted Action EPBD, Adene, Lisbon, Portugal, Detailed Report, 2015. [online] Available at: https://www. epbd-ca.eu/wp-content/uploads/2011/05/CT5_Report_Selected_ examples_of_NZEBs-final.pdf [Accessed: 22.03.2019]

[38] Müller, D., Monti, A., Stinner, S., Schlösser, T., Schütz, T. et al. "Demand side management for city districts", Building and Environment, 91, pp. 283-293, 2015. https://doi.org/10.1016/j.buildenv.2015.03.026

[39] Asan, H., Sancaktar, Y. S. "Effects of Wall's thermophysical properties on time lag and decrement factor", Energy and Buildings, 28(2), pp. 159-166, 1998 https://doi.org/10.1016/S0378-7788(98)00007-3

[40] Mazzeo, D., Oliveti, G., Arcuri, N. "Influence of internal and external boundary conditions on the decrement factor and time lag heat flux of building walls in steady periodic regime", Applied Energy, 164, pp. 509-531, 2016. https://doi.org/10.1016/j.apenergy.2015.11.076

[41] Nowoświat, A., Pokorska-Silva, I. "The Influence of Thermal Mass on the Cooling off Process of Buildings", Periodica Polytechnica Civil Engineering, 62(1), pp. 173-179, 2018. https://doi.org/10.3311/PPci.10132

[42] Dincer, I., Rosen, M. A. "Thermal Energy Storage: Systems and Applications", 2nd ed., Wiley \& Sons, Chichester, England, 2010.

[43] Zhang, Y., Zhou, G., Lin, K., Zhang, Q., Di, H. "Application of latent heat thermal storage in buildings: State-of-the-art and outlook", Building and Environment, 42(6), pp. 2197-2209, 2007. https://doi.org/10.1016/j.buildenv.2006.07.023

[44] Hoes, P., Hensen, J. L. M. "The potential of lightweight low-energy houses with hybrid adaptable thermal storage: Comparing the performance of promising concepts", Energy and Buildings, 110, pp. 79-93, 2016.

https://doi.org/10.1016/j.enbuild.2015.10.036 
[45] Heim, D., Wieprzkowicz, A. "Attenuation of Temperature Fluctuations on an External Surface of the Wall by a Phase Change Material-Activated Layer", Applied Sciences 8(1), 2017. https://doi.org/10.3390/app8010011

[46] Kośny, J. "PCM-Enhanced Building Components, An Application of Phase Change Materials in Building Envelopes and Internal Structures", 1st ed., Springer, Cham, Switzerland, 2014. https://doi.org/10.1007/978-3-319-14286-9

[47] Heim, D., Wieprzkowicz, A. "Positioning of an isothermal heat storage layer in a building wall exposed to the external environment", Journal of Building Performance Simulation, 9(5), pp. 542-554, 2016.

https://doi.org/10.1080/19401493.2015.1126649

[48] Wang, L.-S., Ma, P., Hu, E., Giza-Sisson, D., Mueller, G., Guo, N. "A study of building envelope and thermal mass requirements for achieving thermal autonomy in an office building", Energy and Buildings, 78, pp. 79-88, 2014.

https://doi.org/10.1016/j.enbuild.2014.04.015

[49] Arteconi, A., Hewitt, N. J., Polonara, F. "State of the art of thermal storage for demand-side management", Applied Energy, 93, pp. 371-389, 2012.

https://doi.org/10.1016/j.apenergy.2011.12.045
[50] Arteconi, A., Costola, D., Hoes, P., Hensen, J. L. M. "Analysis of control strategies for thermally activated building systems under demand side management mechanisms", Energy and Buildings, 80, pp. 384-393, 2014.

https://doi.org/10.1016/j.enbuild.2014.05.053

[51] Jędrzejuk, H., Dybiński, O. "The Influence of a Heating System Control Program and Thermal Mass of External Walls on the Internal Comfort in the Polish Climate", Energy Procedia, 78, pp. 1087-1092, 2015.

https://doi.org/10.1016/j.egypro.2015.11.058

[52] Reynders, G., Nuytten, T., Saelens, D. "Potential of structural thermal mass for demand-side management in dwellings", Building and Environment, 64, pp. 187-199, 2013.

https://doi.org/10.1016/j.buildenv.2013.03.010

[53] Clarke, J. A. "Energy Simulation in Building Design", 2nd ed., Butterworth-Heinemann, Oxford, United Kingdom, 2011.

[54] Hensen, J. L. M., Lamberts R. (Eds.) "Building Performance Simulation for Design and Operation", 1st ed., Spon Press, Oxford, Unite States, 2011.

[55] Strachan, P., Svehla, K., Heusler, I., Kersken, M. "Whole model empirical validation on a full-scale building", Journal of Building Performance Simulation, 9(4), pp. 331-350, 2016. https://doi.org/10.1080/19401493.2015.1064480 